

\section{LAS CORTES DE CASTHLA Y LAS RELACIONES EXTERIORES EN LA BAJA EDAD MEDIA: EL MODELO DE ENRIQUE III *}

por

EMILIO MITRE FERNÁNDEZ

Universidad Complutense de Madrid

RESUMEN: Las Cortes castellanas bajo el reinado de Enrique III de Trastamara (13901406) trataron temas de politica exterior en tres ocasiones:

a) De 1390 a 1396, una etapa de apaciguamiento internacional. La Corona de Castilla vivió bajo el signo de las treguas suscritas meses atrás: Bayona (1388) y Leulingham y Monçao (1389).

b) De 1396 a 1402: la guerra mantenida con Portugal-un conflicto de baja intensidad werá objeto de la atención de las Cortes de Segovia (1396), Segovia (1399), Tordesillas (1401) y Toledo (1402).

c) Las Cortes de Toledo en 1406 se reunirán ex profeso para tratar de la guerra a emprender contra el reino de Granada.

De becbo, las cortes del periodo no determinaban la politica internacional de Castilla pero forzaban al poder real a negociar los recursos bumanos y financieros para sostener el esfuerzo de guerra.

Palabras Clave; Cortes castellanas Baja Edad Media. Enrique III de Trastämara. Política exterior.

ABSTRACT: The Cortes of Castile under Henry III of Trastamara (1390-1406) discussed foreign policy on three occasions:

a) 1390.1396: a period of international appeasement. The Crown of Castile lives in the shadow of the truces of Bayonne (1388), Leulingham and Monfao (1389).

b) 1396-1402: the war with Portugal-a small conflitt-is a matter of attention in the Cortes of Segovia (1396), Segovia (1399), Tordesillas (1401) and Toledo (1402).

c) The Cortes of Toledo in 1406 meet with the purpose of preparing the war against the Kingdom of Granada.

* El presente trabajo se encuadra dentro del proyecto de investigación financiado por la DGICYT y del que soy investigador principal: La guerra en la Edad Media bispánica: implicaciones materiales $y$ mentales 
In fact, the Cortes of this period did not determine the international policy of Castile but compelled the King to negotiate buman and financial resources in order to support military actions.

KEY WORDS: The Cortes of Castile Latter Middle Ages. Henry III of Trastamara. Foreign policy.

Dos testimonios parecen buenos para encuadrar lo que se supone protagonismo de las cortes castellano-leonesas del Medievo en la política exterior de la Corona. Traducido a otras palabras - las del conocido aforismo de Clausewitz de que «la guerra es la política llevada por otras vías»- sería tanto como decir la participación de esta asamblea política en los negocios de la guerra.

El primero de tales testimonios abre míticamente la historia del parlamentarismo medieval. Es la solemne Curia leonesa de 1188 tradicionalmente considerada como las primeras cortes de la historia española. Alfonso IX de León prometía en ellas "quod non faciam guerram vel pacem vel placitum, nisi cum concilio episcoporum, nobilium et bononum hominum, per quorum consilium debeo regì) ${ }^{1}$

El segundo testimonio corresponde al período otoñal del Medievo y procede de las Cortes de Ocaña de 1469. Los procuradores de las ciudades recuerdan a Enrique IV que "desde el tiempo del Rey don Enrique II el viejo, de gloviosa memoria, vuestro progenitor, fasta agora, siempre los sennores treyes vuestros anteçesores touieron amistad e confederacion e alianças con los treyes de Françia...) Una costumbre -recuerdanque se había roto al hacer el monarca «nueua amistad e confederaçion e alianças con el Rey de Inglaterras. Tal situación suponia un agravio, entre otras mazones, porque usegun leyes de vuestros reynos cuando los rreyes han de hazer alguna cosa de gran importancia no lo deuen hazer sin consejo e sabiduría de las çibdades e villas prinçipales de vuestros rreynos\%. Tras estos argumentos se solicitaba retomar la vieja alianza con los franceses cuyos reyes eran con los de Castilla los «más poderosos de la christiandad». ${ }^{2}$

¿Estamos ante dos casos aislados? o, por el contrario clas cortes de Castilla a lo largo del Medievo fueron un organismo con capacidad para gestionar o, al menos, orientar la política exterior de la Corona?

Preguntas tan tajantes exigen respuestas plagadas de matices.

Está comunmente admitido que bajo los primetos Tratámaras se vivió una suerte de "edad de oro» de las cortes castellanas. El caso que vamos a tratar aquí va referido al tercer monarca de esta dinastía bajo cuyo reinado se convocaron cortes con una periodicidad casi anual. ${ }^{3}$.

1 Cortes de los antiguos reinos de León y Castilla. vol. I. pág. 40. Madrid 1861. En adelante citaremos solo por Cortes...

J.L. MARTín piensa que la ocasión era propicia para nobles, eclesiásticos y ciudadanos: Alfonso IX veia abrirse, junto al frente musulmán, otro castellano en el que su primo Alfonso VIII manifestaba una marcada superioridad. Las cortes medievales. Madrid 1989. p. 34.

2 Cortes..... vol. III. pp. 809-810.

3 Vid. mi artículo «Los cuadernos de cortes castellano-leonesas (1390-1407). Perspectivas pata su estudio en el ámbito de las relaciones socialesn. Actas de las I Jornadas de metodologia aplicada de las ciencias bistónicas. Santiago 1975 (II. Historia Medieval) pp. 281-292.

Hithania, LIX/1, núm. 201 (1999) 115-148 
Naturalmente, unas asambleas tienen más trascendencia que otras. De algunas cabría pensar que no son más que una prolongación —en localidad distinta- de otras iniciadas días atras ${ }^{4}$. Y, es más que probable que algunas cortes convocadas no llegaran a reunirse. Convocatoria no significa siempre celebración.

Con todo no está de más el preguntarse qué papel desempeñaron las cortes castellano-leonesas en la particular coyuntura internacional de fines del XIV e inicios del XV 5. Una pregunta que arrastra otras varias que van más allá de interrogantes puntuales. Se entra así en terrenos más comprometidos: la propia naturaleza de la institución, sus facultades especialmente en el terreno legislativo, sus limitaciones, etc... Rastrear las relaciones entre política exterior e instituciones parlamentarias en unos años determinados es, posiblemente, un buen desafio para el investigador.

\section{PLANTEAMIENTOS HISTORIOGRÁFICOS GENERALES Y PRECEDENTES}

En fecha anterior a 1936, el Prof. Torres López elaboró un índice de temas susceptibles de estudio a través de la documentación de Cortes. Recogía este historiador hasta veinte cuestiones: la política internacional ocupaba el lugar décimo octavo. ${ }^{6}$

Partiendo de esta idea cabe recordar lo que han pensado al respecto algunos de los especialistas en la materia - clásicos ya algunos- - desde principios del pasado siglo y cómo podemos plantear la cuestión hoy en día.

\section{a) La voz de la bistoriografia:}

Francisco Martínez Marina, en su conocida y clásica obra, sostenía que «los reyes de Castilla se creyeron obligados por constitución a juntar cortes generales, y efectivamente las juntaron en los siguientes casos... pata deliberar sobre los asuntos de guerra y paz, y otorgat garantías en los pactos y alianzas que hubiese parecido conveniente hacer con otros soberanos... cuando por la injuria de los tiempos y de las guetras civiles o externas se observaba decadencia y pobreza en los reinos, despoblación, abandono de la agricultura y del comercio interno y externo...»? ${ }^{7}$

4 Sobre la complejidad de este fenómeno vid. A. Arranz GuZman: «En torno a las supuestas cortes de San Esteban de Gormaz (1394) y de Toro (1398)», en Las Cortes de Castillay Loón. 1188-1998 (Actas de la Tercera etapa) vol. I. Valladolid 1990. pp. 333-340.

5 Las líneas generales de la política exterior del tercer monarca de la casa de Trastámara las planteó L. Sú́rez en "Algunos datos sobre la política exterior de Enrique III», en Hispania 10 (1950) 539-593. Este y otros autores —es mi caso- han redactado diferentes trabajos susceptibles de uso para el tema que ahora nos atañe. A medida que sea pertinente, haremos las oportunas citas.

6 Índice rescatado por J.M. PÉrez Prendes: «Cortes de Castilla y León (1188-1988)», En Revista de la Facultad de Derecho de la Universidad Complutense. Marzo 1986 pp. 79-80.

7 F. Martínez Marina: Teoría de las Cortes. vol. I. Madrid 1813. pp. 32-33. 
Juan Sempere y Guarinos no se ptonunció de forma explícita sobre el papel de las Cortes en la política exterior. Destacó, sin embargo, que el periodo de mayor influencia lo tuvieron en los dos siglos en que Castilla sufrió el flagelo de continuas guerras civiles. La gran política exterior del siglo XVI (expansión en América, campañas europeas) coincidió precisamente con el momento en que los diputados de las ciudades «apenas conservaron una sombra de su antigua representacióny. ${ }^{8}$

Con circunspección se pronunció Manuel Colmeiro al escribir que «solían los Reyes llamar a Cortes para con su acuerdo hacer la guerra y prevenirse de dinero a fin de sostener la campaña con ventaja....En algunas ocasiones juntaban los reyes cortes para pedirles su parecer y consejo acerca del otorgamiento de treguas o celebración de paces»." ${ }^{p}$

Wladimiro Piskorski, en una obra que sigue siendo de obligada consulta, afirma que «dada la dependencia en que el rey se encontraba respecto a la nación en lo telativo a la disposición de las fuerzas militares y materiales de aquella, no podía empezar ninguna guerra si la empresa planeada no había sido autorizada por sus súbditos, y sin contar con el seguro apoyo de los representantes de los mismos teunidos en las cortes. De igual modo que éstas resolvían sobre la finalidad y necesidad de declarar la guerta a este o a aquel teino, tenían también naturalmente el derecho a decidir sobre la terminación de la guerra mediante la conclusión de la paz, y acerca de la firma de tratados de alianza bajo las condiciones que demandaban los intereses o la dignidad nacionabs, ${ }^{10}$

Fácil es detectar en estos textos excesos retóricos y marcados anacronismos. Basta para ello comparar estos pasajes - tanto en el fondo como en la for$\mathrm{ma}$ - con las tesis sostenidas en los últimos años por un J. M. Pérez Prendes: «Respecto a la participación de las Cortes en las grandes cuestiones relativas a la política internacional, no cabe duda que el monarca actua de modo absolutamente soberano, ejerciendo el poder del Estado relativo a las decisiones que hay que tomar. La misión de las cortes es consultiva, peto su consejo no vincula al rey a seguirlo, estando obligado únicamente a darles conocimiento de las empresas que se acometany. "

En una línea parecida, y refiriéndose a los parlamentos europeos del Antiguo Régimen en general, R. Mousnier ha escrito que «El Rey reune asambleas voluntariamente porque las necesita para gobernar y administrar... También

\footnotetext{
XIII.

8. Jempere y Gunkinos: Histoire des Cortès d'Espagne. Burdeos 1815. Introducción p. XI-

9 Vid. vol. de Introduction a Cortes... Madrid 1883. pp. 63-64.

10 W. PISKosRki: Las Cortes de Castilla en el período de tránsito de la Edad Media a La Moderna. 1188-1520. Barcelona 1977 (Sobre la traducción del original de 1897). p. 189.

11 J. M. PÉrez PRENDES: Cortes de Castilla. Barcelona 1974. p. 131. Una posición similar, aunque para un periodo más restringido, adoptan E. S. Procter: Curia y Cortes en Castilla y León. 1072-1295. Madrid 1988. pp. 197-199, y J. F. O'CaLlaGHAN: Las Cortes de Castillay León. 11881350. Valladolid 1989 . p. 126.
}

Hüpania, LIX/1, núr. 201 (1999) 115-148 
potque necesita con frecuencia un complemento de información» sobte los más distintos asuntos, incluidos los referidos a las relaciones con el exterior. ${ }^{12}$

La conmemoración del octavo centenario de la Curia/Cortes de León de 1188 fue la oportunidad de una magno congreso celebrado para revisar la historia parlamentaria castellano-leonesa a lo largo del tiempo. La primera etapa de este importante encuentro científico se decicó a la época medieval y en ella se trataron distintos temas sin que las implicaciones de las cortes en la política internacional dispusieran de una ponencia específica. ${ }^{13}$

En este terreno, J.L. Martín se ha manifestado de forma prudente cuando dice que «también las Cortes de Navarra, Portugal y Castilla son consultadas e intervienen por su iniciativa propia para aconsejar al rey en cuestiones de guerra o de paz y para la confirmación de los tratados internacionales, aunque los datos que poseemos son menos expresivos que los conservados para la Corona de Aragón». ${ }^{14}$

Para el específico caso portugués, Armindo de Sousa ha distinguido entre funciones uprimarias invocadas" que los representantes desearian ejercer pero que no siempre desempenaton, y las «funciones primarias atribuidas» por el poder de forma permanente o ad boc, entre las que se encuentra la guerra y la paz y tregua, que figuran en escasas ocasiones. De forma documentada, cuatro veces entre 1385 y 1490 . De ellas, dos corresponden al período al que dedicamos este trabajo: cortes de Montemor-o-Novo de 1402 y cortes de Santarem de esta misma fecha. Más dudoso es que se traten estos temas en las de Coimbra de $1400 .{ }^{15}$

En cualquiera de los estados ibéricos, la política exterior en estos años sobre ello volveremos más adelante- se identifica con la defensa del reino y con los gastos que consiguientemente acartea.

b) Parlamentarismo y politica exterior en torno a 1400: Hipótesis de trabajo:

Se ha recordado repetidamente que el sistema representativo-deliberante impuesto en las comunidades eclesiásticas (capítulos de las órdenes religiosas y

\footnotetext{
12 R. MOUSNier: La monarguía absoluta en Europa. Del siglo $V$ a nuestros dias. Madrid 1986. p. 78.

13 Las Cortes de Castillay Lén en la Edad Media. Las Actas de la Primera Etapa del Congreso Cientifico sobre la Historia de las Cortes de Castilla y León, celebrada en Burgos entre el 30 de septiembre y el 3 de octubre de 1986, se publicaron en Valladolid en 1988. El area segunda se dedicó a "Organización y Atribuciones» con intervenciones de los Profs. J. GAUTHER DALCI IÉ dedicada a la estructura de la institución y M. A. LADERO y A. MAC KAY dedicadas a implicaciones financieras y monetarias. Solo muy tangencialmente se trataton asuntos concernientes a la política internacional.

14 J. L. Martín: ab. cit. p. 145.

15 A. de Sousa: As Cortes Medievaris portuguesas. 1385-1490. vol. I. Porto 1990. pp. 254-258. A lo largo de este siglo y pico contrasta tan escaso tratamiento de la política exterior con las 37 oportunidades en las que se tocan peticiones y agravios y las 36 en las que se tocan pedidos y empréstitos.
} 
del clero secular bajo los nombres de capítulo, sínodo o concilio) impactó decisivamente en las instituciones civiles (curias generales, consejos, parlamentos) de la Plenitud del Medievo ${ }^{16}$. Se ha sostenido, asímismo, la influencia de las teorías conciliaristas del Bajo Medievo en la potenciación de las asambleas parlamentarias de la época. W. Stubbs habló de un uparlamentarismo Lancasterianon en la Inglaterra de comienzos del XV. Unos años antes Castilla vivió el apogeo de sus Cortes. El reflujo de las tesis proconciliates - al menos en sus manifestaciones más radicales- se acompañó de un retroceso general del poder de los parlamentos en el Occidente ${ }^{17}$. Sempere sostuvo hace casi dos siglos que bajo Enrique III de Tratámara las cortes alcanzaron su más alta consideración e iniciaton su decadencia ${ }^{18}$.

Hablar de la Baja Edad Media como «siglo de la guerra» puede ser un socorrido tópico. Cuenta, sin embargo, con el aval de algunos autores de la época como el francés Honoré Bonet quien en su obra Arbol de las Batallas, de la que circularon en Europa numerosas versiones, dijo que no había ningún rincón del continente, por muy recóndito que fuera, que se hubiera librado del azote de la guetra.

Frente al concepto de guerra se levantaba, obviamente, el de paz. Entre medias, sin embargo, quedaba otro bastante vago que en el Medievo dio extraordinario juego: el de tregua. Según el tratadista antes mecionado, la tregua reportaba tres beneficios: seguridad de los bienes, seguridad de las personas y esperanza de una paz en firme. K. Fowler reconoce que resulta dificil distinguir en la Europa del Bajo Medievo lo que son negociaciones para la paz y negociaciones para establecer una tregua que, en numetosas ocasiones, se renueva de forma rutinaria. Ph. Contamine, para el período que discurre entre 1337 y 1400 ha reconocido 36 años de treguas por 28 de conflagración abierta ${ }^{19}$. No hay que olvidar que el período correspondiente al reinado de Enrique III de Castilla se inserta dentro de lo que conocemos como «las grandes treguas» de 1388 a $1411^{2 n}$ que, como veremos, no estuvieron exentas de sobresaltos.

En los años que preceden al ascenso de este monarca al trono, las cortes fueron escenario de importantes decisiones que afectaron a las relaciones exteriores o de solemnes declaraciones de principios que tenían algo que ver con éstas.

Así, las cortes de Soria de 1380 servirán — como las portuguesas celebradas en ese mismo año - para confirmar acuerdos matrimoniales entre las dos cotonas ${ }^{21}$.

16 R. MOUSNiER: Ob. cit. pp. 82-84.

17 B. GuENÉE: L'Occident aux XIV et XV siècles. París 1991. p. 286. Observaciones que este autor acompaña de las siguientes palabras: «poco a poco el papa y los principes se recuperaron, las convicciones democráticas se apagan, las ordenes de caballeria mueren y la burocratización, largo tiempo bloqueada por las guerras y las revueltas, con su cortejo de desengaños y dificultades financieras, retoma su curson.

18 J. Semplive y Gununos: Ob. ait. p. 137.

19 Cuestiones que sintetizamos en nuestro libro La guerra de los Cien Años. Madrid 1990 p. 79.

20 Ph. Contamine: La guerre de Cent Ans. Paris 1968. pp. 74-80.

21 Cf. J.L. Mhrtin: Ob. cit. pp. 202-203.

Hiqpunia, I.JX/1, núm. 201 (1999) 115-148 
Las Cortes de Coimbra de 1385 zanjarían el tema de la sucesión al trono portugués optando por Juan de Avís frente a las pretensiones de los hijos de Inés de Castro y las de Juan I de Castilla 22.

Las Cortes de Segovia en 1386 sirvieron a este último para hacer un despliegue de mística regia al servicio de la legitimidad de sus derechos frente al pretendiente Juan de Lancaster ${ }^{23}$.

Las Cortes de Guadalajara de 1390, en definitiva, servirían para cauterizar las viejas heridas abiertas por un largo proceso bélico que había entronizado a Enrique de Trastámara en 1369 y había tenido importantes implicaciones internacionales ${ }^{24}$.

\section{c) Enrique III, las cortes castellanas y la política exterior: una retrospectiva bistoriográfica:}

Fernán Pérez de Guzmán, en su conocida galería de personajes, dice de Enrique III: «Del esfuerzo de este rey no se puede saber bien la verdad, porque el esfuerzo no es conocido sino en la práctica y en el ejercicio de las armas, y él nunca ovo guerras ni batallas en que su esfuerzo pudiese parecer, o por flaqueza que en él era grande, que a quien no le vio sería grave de creer, o porque de su natural condición no eta dispuesto a guerras ni batallas» ${ }^{25}$.

Esta imagen un tanto aúlica de la política exterior del tercer monarca de la casa de Tratámara puede ser completada con otras visiones que la historiografía posterior ha dado de él. Unas visiones en las que se hace también una evaluación del papel de las cortes en la gestión de los asuntos internacionales.

Martínez Marina, temitiéndose a ese derecho que -sostenía- ostentaban las cortes a intervenir en los asuntos de guerra y paz, recuerda los casos de 1391 y 1393, los acontecimientos bélicos con Portugal entre 1396 y 1402 y la guerra declarada a Granada en $1406^{26}$.

Manuel Colmeiro, por su parte, dice que Enrique III «a veces exigió tributos y emprendió la guerta sin su [de las cortes] consentimiento; otras con mejor acuerdo, las reunió para pedir gente y dinero, como en las de Toledo de $1406 \% 27$.

Wladimiro Piskorski, recuerda que, aparte de la votación de subsidios, «los Estados dieron directamente su voto acerca de cuestiones internacionales, y su derecho a hacetlo fue confirmado una vez más en las Cortes de Madrid de 1391». Un ejemplo al que el hispanista ruso añadía otros referidos al reinado del tet-

22 M. Cagtano: As cortes de 1385, en Revista Portuguesa de Historia. T.V. Coimbra 1951

23 L. SUńREZ: Juan I rey de Castilla. Madrid 1955. pp. 100-101.

24 E. Mitre: «Las Cortes de Guadalajara de 1390 en el marco de la crisis política del siglo XIVy: en Wad-Al-Hayara 18 (1991) 244-246.

25 Fernan Pérez De Guzman; «Generaciones y semblanzas, en el vol. 68 de BA.E. Madrid 1953. p. 699. Sobre la imagen legada por Entique III vid. mi «La formación de la imagen del rey en la historiografia castellana del siglo XV: Enrique III de Trastámaras, en el 17 Congreso Internacional de Cizencias Histónicas. Sección cronológica. Metodologia La biografia histónica. Madrid 1992. pp. 1131-1138.

26 F. MARTINEZ Marina: Ob. cit.vol. II. pp. 220 a 235.

27 M. COLMİIRO: Ob. cit. p. 406. 
cer Trastámara hasta culminar en las Cortes de Toledo de 1406, en los días finales de la vida del soberano ${ }^{2 y}$.

Los datos con los que los autores se mueven son, lógicamente, los mismos. Las direrencias están en la interpretación que quiera darse.

A un siglo de la publicación oniginal de la obra de Piskorski, la interrelación cortes castellanas-política exterior ha de ser estudiada merced al manejo de distintas fuentes: narrativas, jurídicas, documentales... Sobre ello tuve oportunidad de elaborar el capítulo de un trabajo del que fueron publicadas algunas partes ${ }^{29}$. La dedicada a la cuestión que aquí nos atañe permaneció inédita. Con el transcurso de los años (más de un cuarto de siglo) lo que hoy podemos ofrecer resulta, lógicamente, mucho más enjundioso.

\section{LAS CORTES CASTELIANAS EN UNOS AÑOS DE DISTENSIÓN (1390-1395)}

El 9 de octubre de 1390 moría Juan I en Alcalá de Henares en un desgraciado accidente ecuestre. La Castilla que heredaba un niño, Enrique III, era un reino en paz con su vecinos y con sus antagonistas de meses atrás. El tratado de Bayona (5 de agosto de 1388) entre Juan I y el duque de Lancaster; las treguas de Leulingham (18 de Junio de 1389) que alcanzaban a Inglaterra, Francia, Castilla y Escocia; y las treguas de Monçao (novientbre-diciembre de 1389) entre el monarca Trastámara y Juan de Avís creaban un sistema de seguridad para el conjunto del Occidente como no se había conocido desde mucho tiempo atrás ${ }^{30}$. Añádanse además las treguas suscritas en las cortes de Guadalajara de 1390 entre Castilla y el reino de Granada: «e el rey firmóles las dichas treguas e fizolas asi firmat al principe don Enrique, su fijo; que así las havian de firmar el Rey de Granada e el infante Yuzaf su fijo»" ${ }^{31}$.

La menor edad de un monarca siempe fue en el Medievo una delicada situación. Regularla fue misión de las cortes reunidas en Madrid desde enero a finales de abril de 1391 con una abundante representación ciudadana ${ }^{32}$.

2R W. PISKORSKI: Ob. cit. pp. 190-191.

29 Me refiero a un trabajo que, bajo el genérico título de Estudios sobre la Corona de Castilla bajo Enrique III elaboré con el mecenazgo de la fundación March que le otorgó una Beca en la convocatoria de 1970. Dichos estudios se volcaron en dos temas: las relaciones con Granada y las Cortes. Del segundo se publicaron dos capítulos. Uno con el título «Cortes y política económica de la Corona de Castilla bajo Enrique IIIn en Cuadernos de Historia. Anexos de la Revista Hispania 6 (1975) 391-415. Otro, titulado «Mecanismos institucionales y poder real en la Castilla de Enrique III s aparecido en la revista En la España Medieval Madrid 1981. pp. 317-328.

30 L. SuÁrez: «Castilla . 1350-1406» : Vol. XIV de la Historia de España de R. MEnÉndez PIDAL. Madrid 1966. pp. 276-282).

31 P. López De Ayala: «Crónica del rey don Juan I de Castilla e de León», vol. 68 de B.A.E. Madrid 1953. p. 142.

32 Cf. C. Granda: «Las cortes de Madrid de 1391. Esbozo cronclógico. En la España Medieval Homenaje al Prof. Salvador de Moxó. Madrid 1982. pp. 457-467. También C. Granda y E. MrtRs: "La participación ciudadana en las Cortes de Madrid de 1391. El caso de Murcia». Actas del colo-

Higpania, LIX/1, nür. 201 (1999) :15-148 
La cuestión que más se ha destacado por los historiadores es la de la organización de la regencia del nuevo monarca en la que acabó pesando de forma decisiva la opinión de las ciudades: constitución de un consejo en el que estuvieran representados los tres estamentos; catorce procuradores, ocho nobles y los arzobispos de Toledo y Santiago ${ }^{33}$.

Un tanto enfáticamente se ha hablado de un triunfo del parlamentarismo. A nivel de política exterior se manifestatia mediante la imposición de restricciones al consejo de regencia. La principal rezaba que unon moueran guerra a ningund tey vezino, sin consejo e mandarniento del rregno, salvo entrando enemigos en el rregno e que feziesen mal e dapno eneste regno en voz e nonbre del Rey o algun vezino o contra alguna conpanna, o si alguno fuere desobediente al Rey o a su Consejo; ca entonçe podria e pueden fazer guerra contra aquel Rey en conpanna quela conmençare e contra aquellos queles ayudaren, e ordenar lo que entendieren que cunple a serviçio del Rey e pro del rregno, contra aquell que fuera desobediente al dicho Sennor Rey o a su Consejo» ${ }^{34}$

Se ha destacado (y documentado) el seguimiento hecho desde la Corona de Aragón de las peripecias sufridas por la Castilla de los primeros meses de la minoridad. Ya el 28 de octubre, Juan I «el Cazadon comunicaba a Enrique III el envío como embajador de Guerau de Queralt con cartas de tecomendación que se extendian también, en los meses siguientes, al arzobispo de Toledo, a Pero López de Ayala y a otros prohombres de la corte castellana ${ }^{35}$. Se trataba de un personaje idóneo, ya que había gozado de la confinanza de Juan I de Castilla quien, por sus servicios en la guerra de Portugal, le había hecho señor de San Felices de los Gallegos ${ }^{36}$.

El Canciller Ayala nos dice en su crónica del tercer Tratámara que el de Queralt habló «con todos los señores e perlados e caballeros e procuradores del Regno de Castilla que allí erans ${ }^{37}$. En nombre del rey de Aragón daba todo tipo de garantías y consejos en esa delicada coyuntura, recomendando a su sobrino mantuviera el entramado de treguas suscritas en los años pasados. Las cortes eran, sin duda, un magnífico escenario.

La buena voluntad expresada por el representante de la Corona de Aragón ante el monarca castellano y los tres brazos, no era del todo desinteresada. Por una parte,

quio celebrado en La Rábida y Sevilla (14 a 19 de septiembre de 1981) La ciudad bispánica durante los siglos XIII al XVI. Madrid 1985. vol. II pp. 831-849.

33 Cortes... Vol. II. pp. 485-486.

34 Ibid. p. 488.

35 A. López De MEneses: «El canciller Pero López de Ayala y los reyes de Aragón», en Estudios de Edad Media de la Corona de Aragón 8 (1967) pp. 230 y 249-251.

Del interés de Juan I de Aragón por seguir de cerca la crisis sucesoria castellana puede hablar su desplazamiento desde la zona litoral catalana (Tarragona-Barcelona) a Zaragoza. CE E. Mrire: «Las relaciones castellano-aragonesas al ascenso al trono de Enrique IIU. Anwario de Estudios Medievales 17 (1987) 306.

36. GIL GonzÁlez DAvita: Historia de la vida y bechos del rey don Enrique III de Castilla. Madrid 1638 , p. 32.

37 Pero López de Ayala: «Crónica del Rey don Enrique Tercero de Castilla e de León», en vol. 68 de B.A.E. p. 176. 
porque se hacía hincapie en el apaciguamiento de Castilla con el reino de Granada en momentos en que las relaciones entre aragoneses y nazaries no era muy propicias. El «colchón» castellano parecia de todo punto imprescindible ${ }^{38}$.

Y, por otra parte, porque la correspondencia portada por Guerau de Queralt para distintos personajes de la corte castellana, incluido el marqués de Villena ${ }^{39}$, hacen pensar que el tey de Aragón pretendía crear un grupo de presión en el interior de la corona castellana. Para ello no faltaban bazas: no era la menos importante el bloque de descontentos - el arzobispo Tenorio a la cabeza- con el sistema de consejo de regencia emanado de las cortes.

Sin embargo, el proyecto de un lobby aragonesista tuvo desde un principio escasas posibilidades de triunfar dada la poca fiabilidad de las posiciones tomadas por el marqués de Villena ${ }^{40}$.

El período de reunión de cortes en Madrid en 1391 sirvió también al monarca aragonés para otro tipo de gestiones con Castilla. Por ejemplo, para solicitar el apoyo de Enrique III en las pretensiones del cardenal de Valencia Jaime de Aragón a ciertos beneficios eclesiásticos vacantes a la muerte del cardenal de España Gutierre Gómez de Luna ${ }^{41}$. Y también para solventar algunas cuestiones que afectaban a la raya fronteriza entre las dos coronas.

Concretamente, con fecha 25 de Abril -momento en que se considera pudieran chusurarse has cortes-el rey de Arngón enviaba al de Castilla una carta a propósito de las diferencias existentes por cuestión de límites entre los vecinos de Moya y los de Castelfebib. Por parte aragonesa se había designado como mediador al bachiller en leyes turolense Jaime Jiménez. Se esperaba que por parte castellana - los de Moya al parecer habían desbaratado las señales de demarcación - se procediera a nombrar representantes "en tal manera que todos los escandalos e questiones sean del todo entre vuestros súbditos e los nuestros tiradas e removidass ${ }^{42}$

En menor grado - - a veces solo de forma indirecta - las cortes de Madrid de 1391 sirvieron para orientat la política exterior.

A título de ejemplo, podemos referimos a la embajada enviada por el Rey Carlos III de Navarra para reclamar, sin éxito, que su esposa Leonor de Trastámara volviera a su lado ${ }^{43}$.

38 cf. M. T. FERRER: La Frontera amb ITslam en el segle XIV. Cristiansi sarrains al País Valencià. Barcelona 1988, p. 383, recoge una carta de Juan I de Aragón a los jurados de Valencia de fecha 23 de diciembre en Zaragoza en la que teme que - por no haber tregua ni paz suscrita con Granada por parte de la Corona Aragonesa - se corra el riesgo de una abierta ruptura de hostilidades.

39 E. MrrRE: «Las relaciones ..., pp. 305-306.

41) L. SUAAREZ: «Castilla....» p. 313

41 Archivo de la Corona de Aragón reg. de cancilleria 1875 , fols. 136 v y $137 \mathrm{t}$.

42 Archivo de la Corona de Aragón. Reg. de Cancilleria 1847, fols. 1176 r y 176 v..

El Rincón de Ademuz, aparte de problemas de trashumancia entre ganados aragoneses y valencianos, planteaba problemas entre estados que los diputados resolvian a través de protestas, reclamaciones y amenazas. En relación con Castilla eran tres las cuestiones que los diputados valencianos habian de afrontar: robo y corso de metcancias entre ambos reinos, defensa de derechos de paso y cuestiones de limites. MR MuÑoz POMER: Orgenes de la Generafidad Valenciana. Valencia 1987 pp. 373-374.

43 P. Lóptz De AyaLA: «Crónica... Enrique III», p. 175.

Hi.pania, LIX/1, núm. 201 (1999) 115-148 
El duque de Lancaster tampoco podía ser ajeno a la situación que se había abierto en Castilla a la muerte de su consuegro. Un antiguo petrista, Juan Gutiérrez obispo de Dax, recibió poderes en enero de 1391 para negociar con los regentes lo que había de ser la confirmación de los acuerdos de Bayona y el pago de las cantidades que se adeudaban a Juan de Gante por su renuncia meses atrás al trono castellano ${ }^{44}$.

La embajada del duque no consiguió, sin embargo, abrir fisura en la estrecha alianza que, desde la entronización de los Trastámara, se había establecido entre Castilla y la casa real francesa. El consejo de regencia ratificaría, unos días después de la clausura de las cortes -en Segovia el 27 de mayo- los pactos con la casa de Valois ${ }^{45}$.

Que este acuerdo era pieza maestra de la política exterior Tratámara lo demuestra también otro hecho: que entre julio y agosto de 1391, el bando de descontentos con el consejo de regencia - con Pedro Tenotio al frenteaprobara también la alianza con Francia. Muestra clara, sostiene P.E. Russell, de que trataban de dar un tinte de legalidad a su irregular situación ${ }^{46}$.

Las razones de orden político-militar del pacto se doblaban en aquellos años con otras de índole eclesiástica. Para Francia, Castilla era un peón de primera categoría a fin de mantener al bando aviñonista en época del Cisma. De ahí la importante embajada enviada por Clemente VII con el obispo de San Ponce al frente quien, llegado a Madrid «fabló con el rey, presentes los señores e pertados e caballeros e procuradores del Consejo» ${ }^{47}$. Un personaje el enviado papal que infructuosamente sería utilizado por el consejo para hacer entrar en razón a Pedro Tenorio ${ }^{48}$.

Las cortes de Madrid a las que acabamos de teferirnos tuvieron, de hecho, su prolongación en las de Burgos de 1391-1392 que, en su día, fueton estudiadas a través de la actividad de la ciudad castellana en su gestación y celebración ${ }^{4}$. Los reajustes producidos en el seno del consejo de regencia y las discrepancias entre sus distintos miembros no facilitaron sonadas iniciativas en asuntos de política exterior cuyos más importantes cabos habían quedado ya atados meses atrás.

Refiriéndose a Portugal, la Crónica de Ayala dice que los tutores del rey «ordenaron ciertos mensageros que enviar a la frontera de Portugal a tratar treguas con los de aquel Regno, e enviaron allá al obispo de Sigüenza que decían Juan Serrano, e a Gonzalo González de Ferrera, e a Diego Fernández de Córdoba,

44 L.SUÁREZ: “CASTTLLA...» p. 313.

45 Texto recogido por G. DAUMET: Etude sur lalliance de la France et de la Castille au XIV et au XV siècles. Paris 1898. pp 180-181.

46 P.E. Russell: The English intervention in Spain and Portugal in the time of Edward III and Richard II. Oxford 1955. p 536.

47 P. LÓPEz De AyAlA: «Crónica... Enrique III». pp. 170-171.

43 Ibid. Pp. 173-174.

49 A. Salvá Las Cortes de 1392 en Burgos. Burgos 1891. Es todo un canto al sentido del deber de la ciudad, en el que se incluyen copias de algunos documentos que no tienen relación alguna con los problemas que aquí estamos tratando. 
mariscales de Castilla, e a un Doctor que decían Antón Sánchez, que era Oydor del rey; e fueron allá e trataron las treguas». Una negociación que encontró una dificultad añadida en los meses siguientes a la clausura de las cortes de Burgos: las maniobras del duque de Benavente para casarse con una hija bastarda de Juan de Avís ${ }^{50}$. Los asuntos de familia y la política exterior acaban por ser dos caras de la misma moneda.

Mayor importancia tendrían para las relaciones exteriores de la Corona de Castilla las cortes reunidas otra vez en Madrid en diciembre de 1393. Poco antes, Enrique III había puesto fin a su turbulenta regencia haciéndose personalmente con las riendas del poder.

Tres cuestiones que afectaban a la política internacional se deseaban abordar en estas cortes, según el testimonio que nos ha legado el Canciller Ayala.

La primera: «eran necesarias dichas cortes, por cuanto en el trato de las treguas de los quince años que se pusieron con Portugal, eran ciertos capitulos, que desque el Rey Don Enrique cumpliese los catorce años los confirmase e aprobase, e firmase las dichas treguas segund los capitulos en ellas confirmados) ${ }^{51}$.

La segunda: «Otrosi, etan cumplidoras las dichas cortes porque el rey Don Enrique confirmase las ligas e amistades que avia con el Rey de Francia, segund los tratos que avian en unow ${ }^{52}$.

La tercera cuestión suponía sellar el proceso de apaciguamiento general del Occidente abierto en los acuerdos de Bayona de 1388: que Enrique III «resciviese por muger legítima a la dicha Doña Catalina, por quanto el casamiento era ya firme, pues el rey era en edad de los catorce años, e le otorgabay ${ }^{53}$.

Otros dos temas afectaban también a las relaciones exteriores.

Uno era de naturaleza militar: el reajuste de los ordenamientos de lanzas de las cortes de Guadalajara de 1390. Estos habían estipulado la existencia de un cuerpo permanente de cien lanzas a razón de 1500 maravedís por lanza. Dado que para esta función se elegía muchas veces a vasallos del rey que ya cobraban esa cantidad, se producian ciertas irregularidades que los procutadores deseaban subsanar ${ }^{54}$.

A las cortes de Madrid de 1393 se han atribuido también ciertas medidas que, sin embargo, no fueran exclusivas de esta ocasión: el embargo de beneficios eclesiásticos poseidos por extranjeros. Las rentas confiscadas se pedía fueran dedicadas a la reparación y servicio de las iglesias y de las plazas fronterizas con

\footnotetext{
50 Pero López De Ayala: «Crónica... Entique III» pp. 196-197.

5t Ibid. p. 212. En carta de fecha 8 de noviembre de 1393 el monarca castellano manifestaba ya esta disposición. L. SuÁrez: Relaciones entre Portugaly Castilla en tiempo del infante Don Enrique. Madrid 1960. p. 96.

52 El 16 de enero de 1394 se renuevan las treguas entre Castilla y Francia sin villa de Majoricon (sic). T. RYMER: Foedera, contentiones, literae et cuiuscungue generis acta publica. Londres 1727. vol. VII. p. 763.

53 P. López De Ayala: «Crónica...Enrique III». p. 212.

54 Ibid. pp. 215-216.

Hijpania, LIX/1, núm 201 (1999) 115-148
} 
Granada. Una disposición que no se derogaria sino a ruegos del papa de Aviñón y del rey de Francia a condición de que en el futuro solo se proveyeran prebendas en clérigos del país ${ }^{55}$. Que el problema se planteara o no en estas cortes resulta poco relevante. Lo importante es destacar un tema recurrente que toma la asamblea de los tres estados como el mejor foro teivindicativo ${ }^{56}$.

Pese a todas estas referencias, distintos autores consideran que la capacidad de decisión de las cortes castellanas en el terreno de la alta política internacional era harto limitada. Pérez Prendes ha llegado a esta conclusión a través de la lectura de la carta enviada por Enrique III desde Burgos, el 15 de Julio de 1393, al obispo de Osma. Se le notifica que los embajadores castellanos y portugueses han llegado a un acuerdo para mantener las treguas. Consiguientemente, se le solicita envíe la ciudad un procurador para la próxima reunión de cortes a fin de «aprobar e ratificar las dichas treguas, e las de iurar de guardar, e facer guardar, segunt que el dicho auersario las ha iuradom. Las cortes parece que se limitan, como poder subordinado al rey, a ratificar solemnemente lo que éste ya ha hecho ${ }^{57}$.

Una cuestión ésta sobre la que volveremos más adelante.

Conclusión similar podría extraerse de la promesa de Enrique III de conservar las alianzas con Francia, hecha el 16 de enero de 1394 ante un grupo de magnate laicos y eclesiásticos "et aliis de consilio nostro» ${ }^{58}$. Resulta problemático hablar de unas cortes ya que éstas habían sido clausuradas - según testimonio de la Crónica de Ayala - a finales de diciembre del año anterior.

De todas formas, la reiteración — rutina, podría decirse- de este tipo de compromisos, al margen del escenario en el que se desarrollen, acaba por devaluat sensiblemente su significado.

Los dos primeros años de mayoría de edad de Enrique III estuvieron marcados por el sometimiento de sus díscolos parientes, los «epigonos Trastámatas) en expresión de Luis Suárez ${ }^{59}$.

En un caso concreto, la política interior (o mejor podríamos decir, familiardinástica) y la exterior acaban solapándose. Nos referimos al asunto de la reina Leonor de Navarra, cuya vuelta al reino pirenaico reclamaba insistentemente

55 L. Serruno: Los conversos Pablo de Santa Maria y Affonso de Cartagena. Madnid 1942. pp. 39-40.

$56 \mathrm{Vg}$, en las Cortes de Madrid de 1391, el 18 de abril se invoca el (amucho deservicio e daño a los dichos mis reynos e señorios» derivado de la concesión de beneficios a extranjeros. Ello a propósito de la pretensión del cardenal de San Marcelo de tomar posesión del arcedianazgo de Valderas. Ordena el Rey al concejo de León «que lo non recibades ni consintades recibir a la posesión de los dichos arcedianazgo e prestamos, e si por ventura es recebido, que le non recudades nin consintades recodir con los frutos e derechos de los dichos arcedianazgo e prestamos, ni con parte deellos». Archivo Histórico Municipal de León. caja núm. 4, leg, 14, dos 253. Citado por J. A. MARTín FuErTES y C. ÁLVAREZ: Archiso bistónion municípal de León (Catálogo de documentos). León 1982. p. 121.

57 J. M. PÉrez Prendes: Ob. ait. pp. 134-135. Texto extraido de Lol'rrRAEZ: Colección Diplomática de su Descripción Histórica del abispado de Osma. vol. III. Madrid 1788. pp. 268-269.

58 G. DAUMET: Ob. cit. p. 194. Cf. nota 52.

59 L. Suárez: Nobleza y monarquia. Puntos de vista sobre la Historia politica castellana del siglo $X V$. Valladolid 1975. pp. 71-86. 
su esposo Carlos. Se ha jugado con la hipótesis de que este espinoso asunto se tratase en unas cortes reunidas en Valladolid a finales de $1394^{60}$.

Entre fines de 1395 y comienzos de 1396 pueden datarse ottas cortes celebradas en Madrid, si nos atenemos a un documento que dice: «en consejo e acuerdo del infante D. Fernando mi hermano, e de los perlados e maestres e ricoshombres e cavalleros que conmigo estavan en el dicho ayuntamientos ${ }^{61}$. No se recoge en el, sin embargo, testimonio que afecte directamente a la política exterior.

No habría de pasar mucho tiempo para que ésta volviera a ser centro de atención de las instituciones castellanas.

\section{LAS CORTES CASTELLANAS ANTE UN CONFLICTO DE BAJA INTENSIDAD: EL FECHO DE LA GUERRA DE PORTUGAL (1396-1402)}

Las heridas abiertas por la crisis portuguesa de 1383-1385 tardaron en cicatrizar para la monarquía castellana. Juan I de Trastámara, cuando a fines de su vida -el 27 de abril de 1390 - promulga el Ordenamiento de prelados de las Cortes de Guadalajara se sigue titulando «Rey de Castilla, de León, de Portugal, de Toledo, etc... ${ }^{62}$.

Tan solo unos meses después la situación cambia. En la carta que Enrique III envía a Carlos VI de Francia notificándole la muerte de su padre se titula simplemente Rey de Castilla y León "3. Y en la confirmación general de los privilegios, fueros, y franquezas del reino hecha en las Cortes de Madrid, el 10 de abril de 1391, se elimina igualmente de la retahila de títulos el de rey de Portugal ${ }^{64}$.

Eta evidente que los consejeros del novel monarca pretendían suavizar viejas tensiones con el vecino del occidente peninsular. Una política de gestos que, a medio plazo, no dio los resultados previstos.

60 Cortes que, en principio, hubo intención de celebrar en San Esteban de Gormaz pero que, más tarde, se desplazaron a Valladolid, (desde el 4 de diciembre) a donde dice el rey a las ciudades manden sus procuradores «los quatro primeros dias siguientes que esta carta les fuere mostradas. cf. Colectión de Cortes de los antiguos reinos de España, publicada por la Real Academia de la Historia. Catálogo. Madrid 1855. pp. 45-46. Cuestión también tocada por A. Arranz, an art. cit. p. 339 en donde se recoge el documento en el que se notifica a Burgos el cambio del centro de celebración.

L. SuÁrez habla de Medina del Campo como del lugar último de la reunión, en Estudios sobre el Régimen Monárquico de Enrique III. pp. 107-108. De hecho la villa ferial parece fue lugat de encuentro de los tres brazos si nos atenemos a la carta del rey de fecha 30 de enero de 1395 a los concejos de la merindad de Burgos anunciando el cobro de los servicios votados en cortes en Medina del Campo. L. SUÁREZ: Estudios... pp. 132-139.

61 Academia de la Historia. col. Salvá, vol. 10, fol. $77 \mathrm{v}$. Nota a añadit a la recogida por MonTalvo en las Ordenanzas reales de Castilla. Madrid 1779. pp. 79-84, recordada por A. Arranz: art. cit. p. 334.

62 Cortes...vol. II. p. 450

63 La carta es del 18 de octubre. G. Daumit: Ob. cit. p. 179.

64 Cortes... vol. II P. 507.

Hispania, LIX/1, núm. 201 (1999) 115-148 
La endeblez de ese espíritu de apaciguamiento luso-castellano se puso de manifiesto cuando Juan de Avís, el 12 de mayo de 1396 tomaba por sorpresa Badajoz, pretextando incumplimientos de Enrique III ${ }^{65}$.

¿Qué papel desempeñaría la institución parlamentaria en una crisis bélica que, aunque en tono menor y con distintas suspensiones de hostilidades, se prolonga a lo largo de seis años.?

Para el lado portugués, Armindo de Sousa ha hecho inventario de las reuniones de cortes en este período. De las ocho posibles seis nos son casi desconocidas. Se infieren, sobe todo, de testimonios de Fernão Lopes que nos hablan de gestiones de Juan de Avís para conducir las operaciones militares y para solicitat subsidios a fin de sufragatlas ${ }^{60}$.

Las más documentadas son las de Montemor-o-Novo de 1402. El rey portugués convocaba a la ciudad de Oporto el 10 de febrero con intención de iniciar las sesiones el 1 de marzo ${ }^{67}$. Se deseaba analizar la situación militar ya que las treguas que cansinamente se venían suscribiendo desde fines de 1399 expiraban el 1 de mayo. Por ello se habla de «ordenarmos maneiras que havemos de ter em nossa guerra por nosso serviço e defensa dos nossos regnos» ${ }^{6}$.

Un temor falso ya que, algo más tarde, y tras las negociaciones habidas en Segovia, unas nuevas cortes reunidas en Santarem en el mismo año de 1402 hablan de utermos conselho com algun que para elo mandamos chamab» refirièndose a los acuerdos suscritos con los castellanos ${ }^{69}$.

Del lado casellano «el fecho de la guerra de Portugab» impactó también muy directamente en las distintas reuniones de cortes convocadas entre $1396 \mathrm{y}$ 1402. De algunas no tenemos más que parcas noticias.

\section{a) De Segovia 1396 a Segovia 1399}

Fernão Lopes dice en su Crónica de Joao I que tras la toma de Badajoz, el monarca Avís envió una embajada a su colega castellano (que se encontraba en la ciudad de Córdoba) con Alfonso Vázquez al frente. Su objetivo era, de entrada,

65 Fernĩo Lopes se hace eco de la facilidad con la que la plaza fue tomada depués del intento de resistencia de dos torres que acabaron capitulando. Crónica de D. Joao I. Ed. de M. LOPES ALMEIDA y E. A. de MagalHAES Basto. vol. II. Lisboa 1983. p. 344.

66 En concreto, unas cortes en Santatem en 1396 en las que se recuerdan los incumplimientos castellanos que derivaton en el golpe de mano sobre Badajoz; unas cortes en Coimbra en 1397 y otras en 1398 para recabar ayuda económica; otras en Oporto en 1398 con el mismo propósito; otras en Coimbra en 1400 para tratar de un conflicto que amenazaba reactivarse; y unas en Guimaraes en 1401 para solicitat nuevos subsidios. A. de SousA: Ob. cit. vol. I. pp. 312 a 321.

67 Precisamente el 11 de febremo y desde Montemor -o- Novo, Juan I de Avís dirigía a Gonzalo Vasques, su frontero mayor en la ciudad de Tuy, y a todos los fronteros de la Ribera del Miño, una provisión comunicándoles que había colocado bajo su protección al monasterio de Santa Maria de Oya. Se hacía eco con ello de las quejas que le había transmitido el abad. Archivo Histórico Nacional. Clero R. 77, leg. 1.263, recogido en L. SÁNCriEZ BELDA: Documentos reales de la Edad Media referentes a Galicia (Catálogo de los contservados en la sectiön de Clero del Antrivo Histórico Nacional). Madrid 1953. p. 543.

68 A. de SousA: Ob. cit. p. 323.

6) Ibid. p. 325. También H. Vaquero: Os itinerarios de el-Rei don Joao I. Porto 1988, p. 93. 
inalcanzable: convencer a Enrique III que el golpe de mano no pretendía romper las treguas sino tan solo presionar a los castellanos para que cumpliesen sus condiciones escrupulosamente ${ }^{70}$.

El Trastámara partió de Andalucia hacia el Norte con el propósito de afrontar enérgicamente este delicado asunto. Las cortes reunidas en Segovia en 1396 y de las que, en su momento, se publicó uno de tantos rutinarios (aunque, dada la ocasión, quizás un poco menos) ordenamientos sobre caballos y mulas, estaban fuertemente condicionadas por los últimos acontecimientos de la política exterior. La correspondencia que conservamos del monarca lo muestra de forma patente.

Ásí, el 7 de junio, Entrique III enviaba a uno de sus hombres de confianza, el maestre de Santiago Lorenzo Suárez de Figueroa, una misiva en la que le notificaba la intención de reunir cortes en Segovia (para dar vuestro consejo a mi servicion ${ }^{71}$. En otras cartas se habla, asimismo, de las "cosas que cumplen mucho a mi servicio y a pro e bien de mis regnoss ${ }^{72}$, o se recuerda --el 7 de agosto- - como «sobre la tomada de Badajoz fue acordado se ficieran cortes en esta cibdad de Segovia, porque aquípor todos con tiempo fuese acordado lo que cumplia a mi servicio y a pro y bien destos mis regnos" ${ }^{73}$. El 17 de agosto el rey comunica también al maestre que está tratando asuntos de Francia 73 bis, del Cisma (para lo que ha conversado con el embajador francés a fin de trabajar por la unidad de la Iglesia) y de Portugal, de donde habían regresado los embajadores enviados. Le ruega esté cerca de él para cambiar impresiones sobre este asunto ${ }^{74}$.

Que las cortes de Segovia de 1396 se habían convocado un tanto accidentalmente parece probarlo la solicitud de Enrique III al concejo de Burgos el 10 de Julio. Se le recuerda que aún no ha enviado procurador y se le apremia a que lo haga para tratar "sobre cosas que cumplían e cumplen mucho a mi servicio»"

El antes mencionado ordenamiento de caballos y mulas fue promulgado el 20 de agosto de 1396, incluyéndose la obligatoriedad de alarde anual para todos los vasallos del rey ${ }^{76}$.

70 F. LOPES: Ob. cit. p. 345.

71 Academia de la Historia. col. Salazar. M-6 fol. 320 .

72 Ac. de la Historia. col. Salazar. M-6 fol. 320.

73 Ac. de la Historia. col. Salazar M-6 fol. $320 \mathrm{v}$.

73 bis En concreto, la confirmación de alianzas L. SuÁrEZ: Castilla, e/Cisma y la crisis conciliar. Madrid 1960 pp. 198-200.

74 Ac. de la Historia. col. Salazar M-6 fol. 320 v. y 321.

75 Archivo Municipal de Burgos. SH. nr. 170.

76 Cortes...vol.II, pp. 532-537.

En su momento jugué con la posibilidad de que este ordenamiento fuera impulsado por las especiales condiciones bélicas del momento. eNotas sobre la ruptura castellano-portuguesa de 1396", en Revista portuguesa de Historia. 12 (1969) 215. De hecho se trata de disposiciones de cuya rutina ya advirtió en su momento Colmeiro al remitirse a ordenamientos similares de: Alcalá 1348, Toro 1371 o Valladolid 1385. Lo único original de los de 1396 serian los ordenamientos de lujo. M. Colmeiro: Ob. cit. p. 397. También de 10 de noviembre es la promulgación de unos ordenamientos iguales. Ac de la Historia. col. Abella, vol XIX sin paginar... Todo ello por no recordar otras disposiciones iguales del teinado de Entrique III sobre alguna de las cuales insistiremos más adelante.

Hippunia, LIX/1, núm 201 (1999) 115-148 
Los fechos de Portugal aparecen en el fondo de la pragmática dada en Madrid el 24 de septiembre de 1396. Pudo tratarse de una reunión de cortes o de un simple ayuntamiento: sabemos, al menos, de la asistencia de procuradores de trece ciudades ${ }^{77}$. Enrique III reiteró la prohibición de beneficios eclesiásticos a extranjeros aunque -dato importante- escluyéndose al obispo de Evora y a aquellos portugueses que habían militado al lado de Juan I en la crisis sucesoria lusa ${ }^{78}$

No carecería así tampoco de significado el que unos días antes - el 19 de septiembre y aún en Segovia - el rey de Castilla confirmara el señorío de $\mathrm{Va}$ lencia de Don Juan a favor del infante portugués de este nombre y de sus herederos ${ }^{79}$. Las cortes —o asambleas de tipo similar — eran el mejor escenario para solemnizar la protección real a quienes fueron fieles a la causa Trastámara en una delicada situación 79 bis.

Que el 19 de octubre se pregonara en Madrid el arrendamiento de la manutención de caballos y prohibición de mulas, según los términos fijados en Segovia, hace pensar en un nexo entre dos reuniones mantenidas en lugares distintos pero no muy distantes ${ }^{80}$.

Las convocatorias de cortes castellanas -algunas, como ya hemos adelantado, de dudosa celebración- a partir de 1396 tienen el telón de fondo de los acontecimientos de Portugal. Podría decirse, además, que a dos niveles. Por una parte el de las instrucciones y cambios de impresión del rey con los jefes militares, como Lorenzo Suárez de Figueroa. Por otra parte, el del diálogo del soberano con los representantes de las ciudades para exigirles el esfuerzo económico y humano que las operaciones militares exigían ${ }^{81}$.

Así veremos como con fecha 20 de enero de 1397, en carta expedida en Illescas, el rey convoca cortes para celebrar en Torrijos a partir del 15 de febrero. Se invoca el auténtico leit motiv de la política exterior de estos años: «sobre la toma que fue fecha de la cibdat de Badajos por el adversario de Portugabs. Recuerda, asimismo, que había enviado embajadores al reino vecino —el Mariscal Garcí

7 Ordenanzas de Montakis, vol.I pp. 79-84

78 L. SUȦREZ: Estudios sobre el régimen monárquios de Enrigue III. pp. 142 -148.

79 Ac. de la Historia. col. Salazar. M- 1 fol. 30v. En las cortes de Burgos de 1392 -el 20 de febreto- se habia confirmado ya la donación de Alba de Tormes a petición de dicho Infante y de su mujer doña Constanza. S. Dias ARnAUT: $A$ crise nacional dos fins do seculo XIV. Coimbra 1960 p. 202. Con un pequerio margen de error, la muerte del infante seria en 1397, dejando a su hija María - casada con otro exiliado portugués, Martin Vazquez de Acuña-Valencia, y a su otra hija -BeatrizAlba de Tormes. Ibid. pp. 212-213.

79 bis El 20 de septiembre se ratificatian los acuerdos de amistad con Francia. G. DAUMET: Ob. cit. pp. 203-204.

80 Ac de la Historia col. Abella. vol. XIX sin paginat.

81 De enorme utilidad para ello es la correspondencia del monarca con las ciudades castellanas. A título de ejemplo, la mantenida con Burgos en cuyo Archivo Municipal se conservan algunas importantes piezas. Es de gran provecho la guia publicada por J. A. BONACHIA y J. A. PArdos: Catálogo documental del archivo Municipal de Burgas. Sección Histórica (931-1515). Burgos 1983.

Hìipania, LIX/1, núm. 201 (1999) 115-148 
González y el doctor Antón Sánchez- que retornaron a Castilla transmitiendo «cosas muy feas e muy vergonçosas» de Juan de Avís. En consecuencia, solicita al concejo de Burgos el envío de un procurador upara aver con ellos mi consejo de lo que cumple a mi serviçio e a pro e bien de mis regnos»" ${ }^{82}$.

No hay certeza de que estas cortes se llegaran a celebrar ya que con fecha 25 de febreto, desde Villafranca del Arzobispo, convoca de nuevo a los grandes del reino y a los procuradores para una reunión en Talavera a fin de tratar «sobrestos fechos de Portugaby ${ }^{83}$.

Nos encontramos, posiblemente, ante el momento más duro de la guerra que exigía del Trastámara una amplia movilización de recursos militares ${ }^{84}$.

Se ha especulado con la reunión de unas cortes en Toro en $1398{ }^{85} \mathrm{y}$ otras en Segovia en 1399. En el estado actual de la investigación podemos decir que ambas se celebraron ${ }^{86}$ y que, en estas últimas, se trataron ampliamente temas referidos al conflicto luso-castellano

No vamos a entrar en la prolijidad de datos militares de la contienda, sobradamente estudiada en su día por Luis Suárez y, parcialmente, por otros autores. Simplemente habría que destacar que, a principios de 1399 , las posiciones de los dos contenientes había llegado a un cierto equilibrio. Los portugueses tenían las importantes bazas de la ocupación de Badajoz y Tuy. Los castellanos contaban con un no despreciable flujo de desertores del campo Avís hacia el pretendiente pro-castellano don Dionis ${ }^{87}$.

Podríamos ir más lejos en la detección de cortes convocadas por Enrique III con motivo de la guerra con Portugal.

A las de Segovia -en torno al mes de mayo- de 1399 habtía que añadir otras celebradas poco antes en Madrid si nos atenemos a la carta que el rey envía al concejo de Burgos, el 20 de mayo de ese año, en la que recuerda uel ayuntamiento que yo fise en Madrid este año de la data desta mi carta con el infante Don Fernando

82 Atchivo Municipal de Burgos. SH. nr. 161.

83 Archivo Municipal de Burgos. SH. nr. 171. Recogido también en Colección de Cortes... pp. 46-47.

84 Cf. la carta de 14 de septiembre de 1397 enviada por el rey desde Salamanca al concejo de Burgos ordenanado la movilización de los varones comprendidos entre los 18 y los 50 años. L. SUÁREZ: Relaciones.. pp. 106-107; la enviada también a esta ciudad desde Toro el 24 de octubre de 1397 ordenando se junter peones para la guerra con Portugal, ibid. pp. 110-112; o la cédula de 11 de febrero de 1398 dada en Illescas a los concejos del atzobispado de Sevilla y obispado de Cótdoba para que acudiesen con sus gentes de armas ante Lorenzo Suárez de Figueroa a quien había encomendado la defensa de la frontera con Portugal. Acadernia de la Histotia. col. Salazar M-5, fol. $245 \mathrm{v}$.

85 Apuntado por mi en distintos trabajos, en especial el de «Los cuademos de cortes...» p. 283.

86 Aunque las de Segovia de 1399 no se celebran a finales de 1399 como opina A. ARRANZ. art. cit p. 335, sino a mediados de este año. La carta que el rey envia a Burgos desde Ocaña el 29 de noviembre de 1399 solicitando que se le envíe un procurador para que esté con él el 20 de diciembre no dice que sea a Segovia, sino simplemente sonde quier que yo fuev. Archivo Municipal de Burgos SH. nr. 174.

87 Cf. mi artículo «La emigración de nobles portugueses a Castilla a fines del siglo XIV", en Hispania 26 (1966) 521-525.

Hipania, LIX/1, núm. 201 (19)9) 115-148 
mi hermano, e el cardenal de España e el arzobispo de Toledo e los otros prelados de los mis tegnos e los caballetos del mi consejo e los procuradores de algunas cibdades e villas de los dichos mis rregnos fue ordenado que para continuar la guerra que yo he con el adversario e rregno de Portugal...». Oportunidad en la que se había solicitado un pedido de doce monedas, correspondientes al 1398, de hs que se habían cobrado seis y se deseaban recaudar las otras seis ${ }^{88}$.

Y se añade a continuación en esta misma carta que "con los dichos infante mi hermano e perlados e cavalleros de mi consejo e procuradores de los dichos mis regnos fise ayuntamiento aquí en la cibdad de Segoviay a fin de tomar medidas militares ya que no se estaba dispuesto a cmas alatgamiento de tregua y de pases algunas con el dicho adversation. Mención, sin duda, a una de has muchas suspensiones temporales de hostilidades de las que estuvo jalonado el enfrentamiento luso-castellano de 1396 a 1402. Dichas treguas terminaban a fines de julio ${ }^{\mathrm{k}}$. Por ello, pensaba el rey llamar «a todos mis vasallos que están en las fronteras» mediado el mes de julio. Igualmente deseaba el monarca castellano armar una flota de galeras y naos 10 .

Unos días más tarde, el 29 de mayo en una nueva carta a Burgos, hacía toda una declaración de principios sobre la justicia de su causa en la guerra con Portugal: para "continuar la dicha guerra con la ayuda de Dios que es dador de todas las cosas entiendo entrar por mi cuerpo en el rregno de Portugal lo más poderosamente que yo pudiera a dar batalla al dicho aversario en la qual yo he firme esperança de Dios, que es justo e derechero e sabidor de los fechos, por su juisio maravilloso guardará la mi justicia y el mi buen derecho que yo tengo que abaxará la grant soberbia e orgullo quel dicho aversario tiene e le dará penitencia de las muertes e dapnos y desonras que acá grant sin rraçon e sin justiçia ha fecho a los deste rregno. Para ordenar las cosas que son menester para la dicha batalla e las otras cosas que sobre este a mi serviçio conpliese, fise un ayuntamiento aquí en Segovia con el infante don Fernando mi hermano e con el cardenal de España y otros perlados e rricos homes e caballeros de mi consejo e algunos procuradores de algunas cibdades de los dichos mis regnos, con los cuales, habido mi acuerdo, ordené de ayuntar a toda la más gente que ser pudieses. En consecuencia se daban instrucciones para que los hidal-

88 Archivo Municipal de Burgos. SH. nr. 2742. Se trata de una sumaria referencia recogid: en las primeras líneas la que habla de ese ayuntamiento de Madrid. Pero parece lo suficientc mente explicita.

89) En efecto, con fecha 27 de marzo de 1399, Enrique III enviaba desde Talavera una carta al concejo de Burgos en la que le comunicaba se habian establecido treguas con Portugal hasta el 1 de agosto y solicitaba a la ciudad el envío de un procurador para que estuviese en Segovia con fecha 20 de abril. Se dice en la carta que «por percibimiento de esta guerra son signadas treguas entre mi e el adversario de Portugal fasta primer dia de agosto primero que viene». Por ello les cita para tratar con el infante don Fernando y los otros grandes del reino "algunas cosas que cumple a mi servicio et onrra de mis regnos». Archivo Municipal de Burgos SH. nr. 2542.

90 Archivo Municipal de Burgos. SH. nr. 2742. Toda la segunda parte de este documento hace relación a la movilización de recursos para reactivar a fondo las hostilidades con el «adversario de Portugals.

Fitpania, LIX/1, núm. 201 (1999) 115-148 
gos, caballeros, exentos y otros, acudieran en ayuda del rey con el equipo correspondiente. Como en ocasiones anteriores, Enrique III invocaba, para dar mayor fuerza a su causa, la ruptura provocada por el monarca portugués de la tregua de quince años «furtandome e robandome la mi çibdat de Badajoz»" 1 .

El término «ayuntamiento» utilizado en esta - y en otras habría que añadirocasión por el monarca castellano indujo en su momento a Colmeiro a presentar la asamblea de Segovia de 1399 como una reunión de petsonas principales ${ }^{12}$. Podría hablarse de una suerte de asamblea de notables orientada a la mejor aplicación de los ordenamientos militares ${ }^{93}$

Las demostraciones de fuerza a lo largo de estos años no eran incompatibles con los oportunos tanteos diplomáticos, conducidos en ocasiones por los mismos jefes que dirigian las operaciones bélicas ${ }^{94}$. Lo gravoso de los gastos militares ${ }^{95}$ inducía a impulsar paralelamente una política de apaciguamiento que no se presentaba nada fácil.

Ello parece demostrarlo el que, en los meses siguientes a la clausura de las cortes de Segovia de 1399, Enrique III envie una carta desde Ocaña al concejo de Burgos - 29 de noviembre - en la que, de nuevo, se dice que quiere «tratar sobre algunas cosas que yo tengo que acordar e ordenar assi en fecho de la gue-

91 Archivo Municipal de Burgos SH. nr. 3092. También lo recoge F. Martinez Marina: ob. cit. vol. II. p. 253, extrayendolo a su vez de GIL GonzÁlEZ DÁvilA: Ob. Cit. cap. LX.

92 M. Colmeiro: Ob. Cit. p. 397-398.

93 Cf. a este respecto las cartas enviadas por Enrique III desde Segovia los días 4 y 9 de junio a Murcia y Burgos respectivamente. L. SUAREZ: Relaciones... pp. 117-122.

En la enviada a Burgos en concreto se habla de 30 mil hombres a movilizar A la ciudad castelana le correspondian 450 hombres; 150 caballeros; 150 peones y 150 peones excusados. Archivo Municipal de Burgos. SH. nt. 2624.

También se tomaron en esta oportunidad algunas medidas para compensar a las poblaciones fronterizas por daños sufridos. Así cabe interpretar la prótroga que el 9 de junio de 1399 se otorga a Ciudad Rodrigo, por un plazo de 2 años, de la exención de moneda que habia disfrutado durante cinco, uparando myentes a la pobreza desa çibdat e a los muchos males e danpnos que avedes rreçebido e rresçebides de cada dia por mi serviçio». Circunstancia, que, sin embargo, no le eximía de alcabalas. A. BARRIOS, J. M. MONSALvo y G. del SER: Documentación mediezal del archivo municzipal de Ciudad Rodriga. Salamanca 1988. pp. 88-89.

94 Así, desde Segovia el 3 de mayo — sin duda con el ayuntamiento en funciones- el monarca castellano expedía una cédula a favor de Lorenzo Suárez de Figueroa aprobando los compromisos con el jefe militar portugués, el condestable Nun Alvarez Pereira, para proseguir negociaciones que, eventualmente, levasen a la firma de una paz en serio Ac. de la Historia. col. Salazar. M-5, fol. $245 \mathrm{v}$.

95 A título de ejemplo. Entre marzo y junio, Juan de Velasco toma posesión de los lugares de Valmaseda, Colindres y Limpias. Se trataba de una operación acometida por este personaje en Torrijos el 12 de febrero de 1399 mediante la entrega de una surna que sirvió, precisamente, para sufragar parte de los gastos de las operaciones militares contra Portugal. Academia de la Historia col. Salazar. m. 91, fols I a IIv. El 16 de junio de 1399, Enrique III, desde Segovia, libera a Colindres de la señorialización a cambio de que pagasen - para devolverselos a Juan de Velasco- - la suma de 7.500 florines de oro del cuño de Aragón; la mitad de lo que había costado Ia operación. Ac. de la Historia col. Salazar T. 3 fols. 321 a 324.

Hispanto, LIX/1, núm 201 (1999) 115-148 
rra que yo he con Portugal como sobre otras cosas que tocan mucho a mi serviçio e provecho e ontra de los mis regnos que yo he ordenado que vengan luego a mí los procuradores de çiertas çibdades de los mis rregnos que yo ordené». Se manda que estén con él «onde quier que yo fuer a veinte días del mes de desiembre primero que viene» $\%$

El último gran esfuerzo militar portugués fue dirigido en estos tiempos contra la plaza de Alcantara y se saldó con un fracaso ${ }^{97}$. Castilla y Portugal entraban en el nuevo siglo en una situación de equilibrio similar a la de meses atrás.

\section{b) De Tordesillas 1401 a Toledo 1402}

Aunque no resulte descartable la reunión de algún tipo de cortes o ayuntamiento en 1400 , los testimonios más fiables nos hablan de una importante celebración habida entre Tordesillas y Valladolid en los primeros meses de 1401. Los cuadernos que en su momento publicó la Real Academia de la Historia se complementan con otra documentación de no despreciable interés.

Hace unos años, el Prof. J. F. O'Callaghan analizó un documento procedente del archivo municipal de Burgos, de fecha 23 de febrero que, a partir de la evidencia interna, era datable en 1401. Se trata de una carta de los procuradores de Burgos Fernando García y Gonzalo Ruiz de Villegas en la que manifestaban su malestar por las exigencias reales pata mantener el esfuerzo de guerta. Al concejo de Burgos se le solicitaba el pago de veinte lanzas por los tres meses pasados y a los procuradores en general, la cantidad de 42.500 .000 maravedís para mantener una fuerza armada durante ocho meses. Ese ejército se desglosaba de la siguiente forma:

- 8 mil hombres de armas.

- 10 mil peones.

- 5 mil ballesteros a pie.

- mil ballesteros a caballo.

- 12 galeras y 20 naos y barcas

No se sabe si los procutadores votaron los servicios pedidos ${ }^{98}$.

Lo que sí es cierto es que el rey se avino a compensaciones mínimas (el 2 de marzo) a las poblaciones de la frontera que más habian sufrido los efectos de la guerra: «Et a lo que me pidieron por merçed quela mi merçed mande librar alas çibdades e

96 Archivo Municipal de Burgos SH. nr. 174. (cf. lo dicho en nota 86). Esta noticia se recoge también en Colección de Cortes... p. 47.

97 Enmendando la fecha a F. LOPES, Humberto BAQUERo ha datado la retirada portuguesa de Alcántara el 29 de mayo de 1400 . Ob. cit. p. 85.

9 J.F. O'CAJLAGHAN: «Las cortes de Valladolid -Tordesillas de 1401. Una carta de los procuradores de Burgos", en En la España Medieval 1989. pp. 243-247.

Datadas también en Tordesillas, el 25 de abril y el 16 de mayo son dos cartas dirigidas al maestre de Santiago, con referencias a asuntos de la frontera y que, muy posiblemente, son de 1401. La ptimera da cuenta de haber recibido noticia del repartimiento hecho de seis mil hombres de a pie, ballesteros y lanceros excusados, que se consideraban suficientes para la defensa de la frontera. Ac. de la Historia col. Salazar M-6, fol. 318 y 318v. La segunda habla de la distribución de fuerzas a lo largo de la frontera. Ac. de la Historia col Salazar. M. 6, fols 318v y 319r. Recogido por mi en eNotas sobre la ruptura...s p. 218. 
villas de la frontera de Portugal los dapnos que os son fechos por mis gentes, segunt las pesquisas que yo mande fazer. Sabet que me plaze, e por ende, mando alos mis contadores mayores que ge los libren delas tiertas e merçedes que demi tienen los quelos fezieron segunt fallaren por las dichas pesquisass " ${ }^{\prime \prime}$.

Inquietante podría resultar la petición - reflejo del hartazgo por las movilizaciones- que hicieron los ptocuradores: «me pedian pot merced quelos non demandase Otra gente como fize antannos 100 .

Unos días más tarde, el 15 de marzo, el rey declaraba ante los procuradores que había suscrito treguas con el «aversario de Portugabs hasta el primero de noviembre, como una prolongación del estado de suspensión de hostilidades que en aquellos momentos se vivía. Ordenaba el rey se hicieran los oportunos pregones ${ }^{101}$.

Las cortes de Tordesillas volvieron a plantear el viejo tema de los beneficios eclesiásticos a extranjeros. Y el rey volvió a ptometer guardar das leyes e ordenamientos quel rey Don Enrrique mi auelo e el rey don Iohan mi padre, que Dios perdone, fizierony de forma que si (algunos y estan, que les sean quitados, que asi cunple a mi serviçio» 102.

Las preocupaciones militares de la monarquía castellana stguieton manifestándose a finales de 1401. Desde Madrid, el 25 de noviembre, Enrique III enviaba carta a la ciudad de Burgos recordándole que utobieredes prestos CL omes de a pie ballestetos e lanceros para ir a la guerra quando yo vos enviare llamabs ${ }^{103}$. Se trata de un recordatorio previo a una nueva reunión de cortes.

Esta tuvo lugat en el alcázar de Toledo el 6 de enero de 1402. Se definió como «las cortes e ayuntamiento general de los sus reynos e señorios» llamados para tratar tres cuestiones en especial: el juramento como heredera de la corona de la infana María, la administración de justicia y epor hordenar el fecho de la guerra de Portugal, según que entendía el dicho cardenal (Don Pedro de Frías) había dicho de su parte a los que y se acercaran e diría luego a todos los presentes más largamente " ${ }^{104}$.

En esta ocasión - si a los hechos subsiguientes nos remitimos- el «fecho de la guerra de Portugals parecía llamado a una solución de apaciguamiento en firme más allá de suspensiones de hostilidades por un período limitado de tiempo. Los gestos por ambos lados etan sinceros y así se demostró cuando en

\footnotetext{
${ }^{99}$ Cortes... vol. II, p. 538. Igualmente se hacia eco el rey de las quejas de algunos concejos que reclamaban —después de 16 años-el pago de vituallas que Juan I mandó llevar para la campaña con Portugal.

${ }^{100}$ Ibid. p. 543.

${ }^{101}$ Archivo Municipal de Burgos. SH. nt 2543.

102 Cortes... vol II. p. 543.

${ }^{103}$ Ac. de la Historia. col. Salvá, vol. 10 fols 209 a 210v. También en Archivo Municipal de Burgos. SH. nr. 2997.

104 Archivo General de Simancas. Patronato Real. leg. 7 fol. 59.

Se ha jugado también con unas medidas emanadas de estas cortes, insinuadas por el rey Martín de Aragón —que había hecho algo semejante para sus reinos- de constituir escoltas armadas para dar protección a los barcos castellanos que comerciaban en el Mediterráneo. M.T. FERRER: «Els corsaris castellans i la campanya de Pero Niño al Mediterrani (1404). Documents sobre El Victoriab), en Anuario de Estudios Medievales. 5 (1968), pp. 275-276.
}

Hipaxia, LIX/1, núm 201 (1999) 115-148 
Segovia se abrieron (en junio) negociaciones entre los tepresentantes del rey castellano y el adversario de Portugal. Ferñao Lopes declara que la intención del monarca castellano era "que da paaz the prazia se fallase e ña na tregoas 105.

Tras distintas alternativas se llegaría a la firma de un acuerdo el 15 de agosto de 1402. Los contendientes devolverian las plazas conquistadas, rehenes y prisioneros. Los castellanos abandonaban a su suerte a Don Dionis con lo que, implicitamente, se reconocía a Juan de Avís. Lopes dice de forma categótica: «E desta guissa cesseu emtam ha guerra que amtre Purtuguall e Castella aviaus 106.

Fin de hostilidades - había sido la quinta guerra que en treinta años habian mantenido castellanos y portugueses- aunque, del lado del cronista portugués se reconocieta que «ficava por ffallar na paaz» ${ }^{\circ 0}$. Distinción clara entre lo que significaban unas treguas consolidadas y una paz en toda regla ${ }^{108}$.

«E que se el Rey de Casteella auvese daver batalha com os mouros que el Rey de Purtuguall fose a ella por sua pessoa presemtes ${ }^{109}$. Ese era uno de los términos en que Enrique III deseaba se suscribiesen los acuerdos.

La guerra con Granada sería, en efecto, la más importante preocupación política de otras cortes del tercer Trastámata: las de Toledo de 1406.

\section{EL FINAL, DE UN REINADO: UNAS CORTES PARA UNA GUERRA MUYJUSTA.}

Al igual que en otros tiempos, las relaciones entre Castilla y Granada en los años de tránsito de los siglos XIV al XV eran algo más que un asunto bilateral. Afectaban a las estrategias políicas de todos los reinos ibéricos ${ }^{\text {t10. }}$.

105 F. Lopes. Ob cit. vol. II. p. 406

106 Ibid. p. 410.

107 Ibid. p. 411.

108 Todavía el 21 de octubre de 1406, en Santarem, Juan de Avís recuerda que en las treguas de 1402 se habla de negociar una paz definitiva. Se confiaba que las conversaciones para ello se abririan a partir de los ocho días siguientes a la Pascua de Resurtección de 1407. Archivo General de Simancas. Patronato Real leg. 49. fol. 11.

109) F. LOPES: Ob. cit. vol. II p. 406. Se invocaba para ello el apoyo de Alfonso IV de Portugal en la campaña de Alfonso XI contra los benimerines. Ibib. p. 409.

110 Vid. mi «Las relaciones castellano-granadinas en el marco de la politica peninsular de Enrique III. Notas para su estudion En Cuadernos de Estudios medievales. 2-3 (1974-5) 313-320.

Para las estrictas relaciones entre Castilla y Granada vid. más extensamente mi «De la toma de Algeciras a la campaña de Antequera (Un capítulo de los contactos diplomáticos y militares entre Castilla y Granada)». en Hispania 32 (1972) 72-122. Attículo a complementar con otro también de mi autoria: «Enrique III, Granada y las cortes de Toledo de 1406» en Homenaje al Prof. Alarcos Garcia. vol. II. Valladolid 1966.

Otros trabajos que se han publicado posteriormente sobre la política granadina del tercer Trastámara -incluso alguno que se pretende crítico- no han añadido practicamente nada nuevo a lo que yo escribí hace veintitantos años. 
En el caso aragonés eran frecuentes las incursiones entre uno y otro lado a través del Adelantamiento de Murcia y a lo largo de la franja costera ${ }^{111}$. En 1403 un nuevo factor se unió para enrarecer más el ambiente: la ruptura de relaciones comerciales ordenada por Enrique III al cerrar los puertos y pasos de metcancías con Aragón y Navarra ${ }^{112}$. La desconfianza llegó a tales extremos que, algunas movilizaciones castellanas en el año 1405, se creyeron en Atagón una amenaza, cuando sólo eran simples medidas pteventivas contra los granadinos ${ }^{113}$.

A principio de octubre de 1406 nazaries y castellanos suscribieron un acuerdo que no tuvo efectividad alguna ya que se solapó con un violento choque en alto de los Collejares - cercanías de Quesada - en el que los castellanos lograton rechazar a los granadinos, aunque a costa de graves pétdidas 114 . La reconocida templanza de Enrique III en cuanto a política exterior llegó a su fin. En las semanas siguientes decidió organizar una campaña a fondo contra el último teducto musulmán en la Península.

Para ello necesitaba recabar el apoyo de las villas y ciudades del reino. Con esta finalidad convocó, el 10 de noviembre, cortes en Toledo para iniciar las sesiones antes del día de San Andrés.(30 de noviembre). En la carta a los concejos se hablaba de shazer guerta por mat i tierra a él (Muhamed VII) i a los demas moros enemigos de la fes, para lo cual era menester reclutar gente de guerra, ballesteros, lanceros, galeras y todo tipo de pertrechos. Para todo ello eran «forçosas muchas costas i despensas" ${ }^{115}$.

$\mathrm{El}$ autor de la Crónica de Juan II, antes de introducirse en el reinado de este monarca y con ánimo de cubrir las lagunas dejadas por su predecesor Peto López de Ayala, dedica las páginas iniciales a los últimos días de la vida de Entrique III. En concreto, a las Cortes reunidas en el Alcázar de Toledo en diciembre de $1406^{116}$.

111 Vid. para ello el exhaustivo estudio de M. T. FERRER: La frontera.. citado en nota 38.

112 Cuestión tratada, entre otros por J. TORRES FONTES: «La regencia de D. Fernando de Antequem. Política exterion). en Anales do la Universidad de Munia, 1959-1960; y por T. FERrer: «La ruptura comercial amb Castella i el seves repercusions a Valencia (1403-1409)y, en Actas del I Congreso del Pais Valenciana 1970.

113 Así, el 2 de julio de 1405, desde Barcelona, Martin el Humano tuvo que calmar a los diputados de Tarazona que se sentian inquietos por estos preparativos. Cf $\mathrm{D}$. Girona: Itinerari del Rey Marti, en Institut d'Estudis Catalans. Anuari. 1913-1914. pp. 524, 547 y 576.

114 E. MrrRe: «De la toma de Algeciras a la campaña de Antequera..» pp. 117 a 120.

La batalla de los Collejares la dati en 1407 Juan de ArQueluada en su Anales de jaén. Ed. de M. GONZÁLEZ JIMÉNEZ. Granada 1996. p. 15. El actual editor de este texto ha tenido buen cuidado en hacer las pertinentes puntualizaciones en el detallado aparato crítico y ha situado el choque el 6 de octubre de 1406.

115 Carta enviada por Enrique III al concejo de Murcia que, sin duda, puede servir como modelo. F. Martinez Marina: Ob. att. vol I. pp. 168-169. Extraída, a su vez de Cascales: Dijoutsas históticos de la ciudad de Munia Madrid 1622. pp. 179-180.

116 La versión que se recoge en el vol 58 de la Biblioteca de Autores Españoles y arribuida a Fernán Pérez de Guzmán fue eenderezada al muy alto e muy poderoso Rey don Carlos nuestro señor por el Doctor Lorenzo Galindez de Carvajahs, cubre las pp. 259 a 271 . En su momento fue la versión que utilizamos para la redacción de «Enrique III, Granada y las Cortes de Toledo de 1406». Con posterio-

Higpania, LIX/1, núm. 201 (1999) 115-148 
Para el tema que aquí nos concierne - las relaciones exteriores- hay dos cuestiones fundamentales a las que es necesario referirse. Ambas las planteó ante los tres brazos el infante don Fernando en nombre de su hermano el rey Entique que llegó moribundo a la ciudad. Por una parte, era la justificación ideológica de la guetra a emprender. Por otra, era el forcejeo con los procuradores a fin de logtar los subsidios necesarios que hicieran viable una amplia movilización militar.

\section{a) Una guerra justa:}

El 13 de diciembre 116 bis, en el discurso de apertura de las cortes, Don Fernando solicitó de los presentes su opinión sobre «si la dicha guerra hera justa, e si se deuia fazens ${ }^{17}$.

La respuesta de los tres estados fue afirmativa.

El infante, como Señor de Lara y cabeza del estamento nobiliario, dijo que «la guerra es muy justa e muy de serviçio de Dios, e que se deve haçer, como el rey mi señot e mi hermano le tiene en voluntad de lo hazes) ${ }^{118}$.

Por el brazo eclesiástico le hubiera correspondido pronunciarse al arzobispo de Toledo. La sede se encontraba a la sazón vacante en estricta aplicación del principio - tan tratado en cortes-- de no otorgar beneficios eclesiásticos a extranjeros. Como tal se había considerado al candidato preconizado tres años atrás: Pedro de Luna, sobrino del papa - del mismo nombre en el mundoBenedicto XIII, en virtud de su condición de aragonés ${ }^{119}$. La voz de los eclesiásticos la tomó así el obispo Juan de Sigüenza: «digo que la guerra es muy jus-

ridad, Juan de Mata CARriazo editó la primera parte de la Crónica bajo la autoria de Alvar Garcia de Santa María. Madrid 1982. Las peripecias de las Cortes de Toledo de 1406 quedan recogiadas en las pp. 5 a 17. El fondo de ambos textos es prácticamente idéntico. Sólo se dan algunas diferencias en cuestiones menores de caracter formal o de redacción.

t16 bis De hecho, la movilización se había iniciado ya, al menos en Murcia, el 3 de diciembre. D. MENJOT: Fissalidad y sociedad. Las murcianos y el impuesto en la Baja Edad Media. Murcia 1986 , p. 253.

117 A. Garcia De Santa Maria: Ob. cit. p. 7. En la edición de B.A.E. se recoge el discurso atribuido al infante en tétminos similares. p. 259.

118 Alvar Garcia De Santa Marja: Ob. cit. p. 8. En B.A.E. p. 260.

119 Tal decisión se fraguó el 28 de abril de 1403 . Entique III en un solemne acto, ante prelados y caballeros reunidos en Valladolid, restituía la obediencia a Benedicto XIII que habia sustraído en diciembre de 1398 . Sin embargo el monarca, actuando como "guardador, protector y defensor de las iglesias de sus dominios», se negó, frente a los intentos del pontífice aviñonense, a revisar los beneficios otorgados en los tiempos de la sustracción. Medida que fue acompañada de la negativa de cubrir esa vacante de la sede toledana. J. TEjadA Y Ramiro: Colección de cánones y de todos los concilios de la Iglesia de España y América. vol. III. Madrid 1851 p. 625-626. La no revocación de las prebendas otorgadas en tiempos de la sustracción era «por cuanto se daría a entender que la dicha sustracción non abria sido fecha derechamente». Biblioteca Nacional. mss 13116. Dd 138, fols. 88 a 93 .

No parece en ninguin caso que sean reuniones de cortes en las que se adoptan estas decisiones.

Hispania, LLX/1, núm. 201 (1999) 115-148 
ta, e que se deue fazer: e todos estamos prestos de fazer las cosas que son en serviçio de Dios e del Reys ${ }^{120}$.

$Y$ en cuanto a los procuradores: «fablose por todos que la guerra hera muy justa, e que se deuia fazer, e yr muy poderoso a ellas ${ }^{121}$.

Una guerra justa y una guerra que también se pretendia - valga el evidente anacronismo- total. Los procuradores explicaron bien esta filosofia al decir que la guerra utan justa es, contra los moros, enemigos de la fe, por los grandes fallesçimientos e quebrantamientos de juramentos e de verdades que el dicho Rey de Granada ha fecho al dicho señor Rey. E que hera e es grande razón quel dicho señor Rey faga la dicha guerra poderosamente, por mar e por tierra, porque su corona $\mathrm{e}$ honrra a su servicio de sus Reinos se ha guardado e llevado adelante, con mayor acreçentamiento de señorios» ${ }^{122}$. Una felonia de la envergadura de la cometida por el monarca granadino exigía una respuesta contundente.

Esa misma dimensión religiosa que se pretendía dar al conflicto, planteó las primeras contradicciones entre los brazos ciudadano y eclesiástico. Este último alegaba que uno heran tenudos de derecho de pagar en la costa desta guerra». Un argumento contra el que los procuradores esgrimieron otro: que los eclesiásticos «tienen gran sinrrazon en esto que dizen, que pues es guerra contra ynfieles, también deven en ello pechar e pagat, e poner y las manos como nosotros” ${ }^{123}$.

\section{b) Las dificultades de una financiación:}

La brillantez de un principio sobre el que los tres brazos estaban de acuerdo - la justicia de la guerra - chocó de inmediato con otra cuestión mucho más prosaica: la financiación del esfuetzo militar.

El cálculo de efectivos a movilizar era el siguiente:

- Diez mil lanzas.

- Cuatro mil jinetes.

- Cincuenta mil hombres de a pie «dar çeros e ballesteros, demas de los del Andaluziay.

- Mil ballestetos a caballo.

- Treinta galeras armadas y cincuenta naos, además de otros pertrechos ${ }^{124}$.

Las cifras manejadas eran superiores a las barajadas en 1401 con motivo de la guerta con Portugal. Y los gastos previstos eran, consiguientemente, más elevados: mantener semejante fuerza durante un periodo de seis meses supondría un gasto algo superior a los cien millones de maravedís ${ }^{125}$.

\footnotetext{
120 Alvar García De Santa María: Ob. ait. p. 8. En términos parecidos se recoge el discurso en B.A.E. p. 260.

${ }_{121}$ Alvar Garcia De Santa Marja: Ob. cit. p. 10. En la edición de la B.A.E. se añade además que uera la primera guerra en que (el tey) ponía las manos». p. 261.

122 Alvar Garcia De Santa María: Ob. cit. p. 13-14.

123 Ibid. p. 15. En B.A.E. p. 261.

124 Alvar Garcia De Santa María: Ob. cit. p. 14.

125 Recogido en mi «Entique III, Granada y las cortes de Toledo de 1406». p. 4

Hispania, LIX/1, núm. 201 (1999) 115-148
} 
En la mente de los procuradores estaba, sin duda, presente la sangría económica que había supuesto la última confrontación bélica con el adversario de Portugal. De ahí las reservas de los representantes ciudadanos que consideraron que «non podría complir esta carga tan grande». Se sacó a colación el tema de las alcabalas que habían sido otorgadas por el reino para la "conquista de los moros» en tiempo de Alfonso XI y que luego el tiempo había convertido en "derecho çierto e acostumbrado" 126 .

Al final se legó a una solución de compromiso suscrita el 15 de diciembre. Los procuradores aprobaron un presupuesto de $\mathbf{4 5}$ millones para los siguientes seis meses aunque plegándose a que upasados los seis meses, si más oviese menester para disponer en este dicho año, que los pudiese echar (el rey) sin llamar a cortes» ${ }^{127}$. Una solución que se disfrazaba de deferencia del poder para con las ciudades que, así, se ahorrarían los gastos de volver a enviar nuevos procuradores.

En la Navidad de 1406 (primer día de 1407 en el cómputo de Navidad) moría Enrique III. La magna campaña que se avecinaba y para la que se habían convocado las cortes de Toledo, sería un magnífico instrumento de propaganda para quien había dirigido sus sesiones: el infante don Fernando ${ }^{128}$.

\section{ESTADO, POLITICA EXTERIOR Y CORTES CASTELLANAS EN TORNO A 1400: UNA POSIBLE VALORACION GLOBAL}

Para que pueda hablarse de política exterior se requiere la existencia de un estado. Por estado - _-n el sentido actual del término- se entiende inuna comunidad asentada en un territotio y dotada de una organización política independiente, entendiendo por tal una otganización de poder dirigida al gobierno de una comunidad, y de un poder que es originario, es decir, no derivado de otro poder superions ${ }^{129}$.

La Corona de Castilla en tiempos de Enrique III ¿̧se ajustaba a este esquema?

Salustiano de Dios sostiene que en la Castilla de las últimas decadas del siglo XV se dieron condiciones suficientes para hablar de un estado. El ambiente para ello se había ido preparando a lo largo de la crisis bajomedieval, con la

126 M.A. LADERO sostiene que en algún momento del reinado de Erique III fue, precisamente, cuando la alcabala se convirtió en renta fija y ordinaria sin necesidad de concesión aprobada en cortes. «Ingreso, gasto y política fiscal de la corona de Castilla, desde Alfonso X a Enrique III (1252-1406)y En Hacienda Pública española. Institutos de Estudios Fiscales, núm. 9. p. 44.

127 Alvar Garcia De Santa Maria: Ob. it. p. 17.

128 M. A. LADERo destaca cómo a partir de este momento cualquier personaje con ambiciones tendrá en la frontera granadina un excelente medio de promoción. Granada. Historia de un pais islámico. Madrid 1979 p. 133.

129 A. LATORRE: Introducción al Derecbo. Barcelona 1971. p. 20.

Hispantia, LIX/1, núm. 201 (1999) 115-148 
aparición de una conciencia de reino superior a la de otro tipo de jurisdicciones o corporaciones tipo señorio, concejo, cabildo, etc... ${ }^{130}$.

Habtía que añadir también que en ese ambiente tuvo enorme importancia una sustancial continuidad - ya que no homogeneidad- territorial. En efecto, los acuerdos de Alcañices y Torroellas - de 1297 y 1304 respectivamente- consagraton una solidificación de fronteras con Portugal y la Corona de Aragón. Los manejos diplomáticos que acompañaron a los conflictos en los que se vio implicada Castilla en los años siguientes, especularon con el porvenir de amplias franjas fronterizas: las Provincias Vascas, el reino de Murcia, una respetable porción de tierra en la linde castellano-portuguesa, etc.. ${ }^{131}$. Sin embargo, las sucesivas treguas y paces que se fueron suscribiendo no hicieron mas que reafirmat el statu quo territorial. Las crisis internacionales de la segunda mitad del siglo XIV no aumentaron las dimensiones de la Corona de Castilla pero la consolidaron como primera potencia peninsular.

¿Qué papel desempeñaron las asambleas parlamentarias en el discurrir general de la política exterior del Bajo Medievo?

Un hecho previo hay que tener en consideración: expresiones como estado, política exterior o as ambleas representativas han de ser interpretadas dentro de un contexto que poco tiene que ver con el actual. Pensar en términos de analogía sería incurrir en ese pecado de anacronismo en el que cayeton algunos autores del pasado siglo.

\section{a) El sentido de las relaciones exteriores y la valoración de la guerra:}

La política exterior y su manifestación más crispada - la guerra- se desenvolvieron durante buena parte del Medievo en un contexto familiar o -si se quiere utilizar un concepto más amplio- feudal ${ }^{132} \mathrm{~J}$. Strayer piensa que, a finales del siglo XIII y pese los distintos intercambios diplomáticos, el concepto de «relaciones exteriores» tenía aún pocas posibilidades de vida ${ }^{133}$.

130 S. de Dios: «El Estado moderno ¿Un cadáver historiográfico?» En Realidad e Imágenes del poder. España a fines de las Edad Media. Valladolid 1988. pp 393-394.

131 Cf. mi «Politica exterior castellana y reestructuración nobiliaria bajo los primeros Trastámaras (1369-1406)", en III Jornadas Hipano-Portuguesas de Historia Medieval. La Peninsula Ibérica en la Era de los Descubrimientos, 1391-1492, celebrada en Sevilla 25-30 noviembre de 1991. T. I. Sevilla, 1997, pp. 531-532.

132 De ahi la utilización de expresiones como interfeudal o intermonárquico para definir las relaciones entre poderes en la plenitud medieval. Expresiones «estricta y lingüisticamente inaceptables, pero de alta utilidad semántica» y preferibles al anacrónico sinternacional». Vid. E. PASCUA: Guerra y pacto en el siglo XII. La consolidación de un sistema de reinos en Europa Occidental. Madrid 1996. Introducción. p. XXI.

De ahí también la comodidad de una expresión aparentemente contradictoria pero que se ha revelado altamente operativa: la de "monarquía feudals popularizada en su momento por Ch. PETIT DUTAusus: La monarchie feodale en France et en Anglaterre X-XIII siàcles. Paris 1933.

133 J. StRAYER: Sobre Los origenes medievales del Estado moderno. Barcelona 1981 p. 112.

Hiiffania, LIX/1, núm. 201 (1999) 115-148 
En los años siguientes, la Corona de Castilla podía poner en juego medios aún muy pobres ${ }^{134}$.

Los cambios que se van produciendo de forma paulatina a medida que avanzamos en el siglo XIV hacen que la guerta y la diplomacia adquieran una mayor complejidad e impacten en todos los organismos del estado, asambleas parlamentarias incluidas. Pese a ello, el toque familiar y el condicionante feudal no desaparecerán del todo ${ }^{135}$.

Los recelos hacia el vecino planteados en las asambleas de los tres estados se presentan casi siempre en términos de defensa del reino ${ }^{136}$. Para la Castilla de fines del siglo XIV, el caso más dramático se dará en las Cortes de Segovia de 1836: Juan I de Trastámara identifica sus derechos al trono con la propia dignidad e integridad del reino invadido por portugueses e ingleses en supuesta connivencia con los granadinos ${ }^{137}$.

Es una de tantas manifestaciones del principio de guerra justa que -como ya hemos anticipado- vuelve a darse, y por otros motivos, en las Cortes de Toledo de 1406. En este último caso no es solo por defenderse de una agresión exterior sino también por (cecobrat las tierras que los moros tenían usurpadas»" ${ }^{138}$. El cliché ideológico de la «pérdida de España) seguía funcionando a principios del siglo XV ante un foro representativo de las tres fuerzas sociales del reino.

La guetra es justa - de acuerdo con los más tancios esquemas- siempre que vaya orientada a la recuperación de un bien aviesamente arrebatado y, pata mayor escarnio, por enemigos de la fe. La situación que se juzga en diciembre de 1406 requería, más que ninguna otra, el concurso del pueblo que debía asistir al rey. Ya en Las Partidas se hablaba de la gran culpa de no asistir al monarca cuando entraba «a ganar algo en tierra de enemigos» y mayor culpa cuando no se le asiste si «los enemigos le entran a fazer daño en la suya» ${ }^{13 \%}$.

En el mismo 1406 precisamente moría el civilista italiano Pedro Baldo de Ubaldis, para quien la guerra justa había de reunir las condiciones fijadas años atras por Lorenzo Hispano, Juan Teutónico o Raimundo de Peñafort: declarada por persona secular y no eclesiástica; conducida para recuperar o defender

134 L.V. Díaz MARTín: « Castilla 1280-1360 ¿Politica exterior o relaciones accidentales?h en Génesis mediexal del estado moderno. Castilla y Navarra (1250-1370) Valladolid 1987 pp. 125-147. Destaca la falta de coherencia en cuanto a sistemas de alianzas, circunstancia por la cual dificilmente podria hablarse de una política auténticamente internacional.

135 Pata el caso castellano dos hechos avalan esta idea. Uno, el de las relaciones con Navarra -huida a Castilia de la reina Leonor-en las que un problema familiar crispa en los años finales del sigło XIV lo que en principio habia de ser una política de buen entendirniento entre dos monarcas. Otro, el de las deserciones de miembros de la nobleza de uno a otro reino del que hemos hecho mención a propósito del Fecho de la guerra con Portugal.

136 Para el caso aragonés vid. L. GonzÁLEZ ANTón: Las contes de Aragón. Zaragoza 1978 p. 104, que hace referencia al periodo 1349-1410. También E. SARASA: Las cortes de Aragón en la Edad Media. Zaragoza 1979. p. 98.

137 Cortes.. vol. II. pp.

138 En B.A.E. vol. 58. p. 262.

139) Part. Segunda. Tit. XIX ley IV. 
una patria; hecha como último recurso; conducida sin odio; y declarada por la autoridad de un principe ${ }^{140}$. A los representantes de los tres estados les parecía evidente en 1406 que estos requisitos se reunían de pleno ${ }^{141}$.

b) Papely razón de ser de las cortes en este contexto:

Un viejo aforismo que se remonta al derecho justinianeo dice que do que atañe a todos por todos debe ser aprobadon. Tal precepto se reiteró a lo largo del Medievo en los más diversos textos. Algún autor relevante ha sugerido que su utilización en Las Partidas, aplicado al terreno militar, supondtía el inicio del servicio obligatorio de armas en caso de invasión del reino ${ }^{142}$.

El Canciller Ayala recuerda el aforismo en un pasaje de una de sus obras más populares: «E sean con el rey al consejo legados/ prelados, cavalleros, doctores e letrados/ buenos omes de villas, que ay muchos onrados/ e pues a todos tañe, todos sean llamados» ${ }^{143}$. Se ha dicho que en este y en otros casos no se trata tanto de aprobar como de participar ${ }^{144}$.

En este sentido se pronunciaron las cortes de Toledo de 1406: sporque con acuerdo e consejo de todos la guerta se comenzase» ${ }^{145}$.

En este vocablo - consejo- está una de las claves en tomo a la que ha girado buena parte de la especulación sobre el valor de las asambleas parlamentatias medievales.

¿Expresaba este consejo la lealtad a un Estado con unos limites ya bastante definidos? ¿Un Estado, por tanto, con una política exterior dotada de una cierta coherencia que tenía en la guerra uno de sus instrumentos?

Revisemos algunas situaciones.

Se ha dicho que la asamblea que convocó en París en 1302 Felipe IV pretendía ser una muestra, frente al papa Bonifacio VIII, de la unanimidad nacional en torno al monarca francés. Habrá que esperar, sin embargo, a los primeros descalabros de la Guerra de los Cien Años para que los Estados Generales ejerzan un protagonismo por erigirse en organismo de control de los subsidios solicitados por el rey. Las reuniones coinciden así con los momentos

140 Recogido por Ph. Contamine: La guerre an Mojen Age. Paris 1980. pp. 449-450.

141 El Canciller Ayala que vivió en estos años y que participó activamente en distintas reuniones de Cortes no manifiesta hacia la guerra unos sentimientos tan justificativos. En su conocido $L i$. bro rimado del Palafio parece mostrarse contrario a cualquiera de sus manifestaciones: «e si la guerra sigue, todo esto es perdidon Ed. de J. JoSET. vol. I. Madrid 1978 p. 213 ... e «si el rey oviere guerra, siempre sera quexado/ de muchos pensamientos de coraçon turbado/ el reino en grant quexa, de peligros tribuladon ibid. p. 255. Las experiencias padecidas por este personaje $\longrightarrow$ dos prisiones tras las derrotas de Nájera y Aljubarrota- parecen estar en la raíz de este presunto pacifismo.

142 JA. MarAVALL: «La corriente democrática medieval en Esparia y la fórmula «quod ommes tangits, recogido en Estudior de Historia del pensansiento españoh Edad Media. Madrid 1983. p. 166.

143 P. López De Ayala: Libro... vol. I. p. 148.

144 Así lo recuerda el propio J.A. Maravalt: Ob. cit. p. 172. para referirse a las Cortes de Segovia de 1386.

${ }_{145}$ Tal y como se recoge en la «Crónica de Juan IL» ed. B.A.E. vol. 58. p. 259. En términos casi idénticos se pronuncia Alvar Garcí De SANTA Marfa: Ob. cit. p. 6.

Hispanis, LJX/1, núm. 201 (1999) 115-148 
de debilitamiento de la autoridad real ${ }^{146}$. La guetra, como manifestación más crispada de las relaciones entre estados, potenció el parlamentarismo en el conjunto del Occidente ${ }^{147}$.

En el caso castellano, y para la época que aquí tratamos, hay varios ejemplos en los que se hace evidente - vía cortes - esa continuidad del Estado hacía el que los súbditos expresan su lealtad.

El primero se da tras el descalabro de Juan I en Aljubarrota: serán las Cortes de Valladolid de 1385 y las de Segovia de 1386 de cuya importancia ya hemos dado las oportunas referencias.

El segundo ejemplo lo proporcionan las Cortes de Guadalajara de 1390 o, mejor aún, sus prolegómenos. Juan I sometió a las personas de su Consejo nada menos que la división de sus estados. El quedaria con Andalucía, Murcia, el señorio de Vizcaya y las tercias. Su heredero Enrique, príncipe de Asturias, pasaría a regir Castilla y León y ostentaría también el título de rey de Portugal cuyos naturales - se suponía un tanto ingenuamente- no recelatían ya de un acercamiento dinástico que se había malogrado en los meses anteriores ${ }^{148} . \mathrm{El}$ testimonio de Ayala es tajante al respecto. Los del Consejo se opusieton categóticamente a estos planteamientos argumentando que los de Portugal «en ninguna manera vos obedescerán e que sobre esto moritán o se perderán». En relación con la partición de reinos se recuerdan las desdichas pasadas en tesitutas semejantes. En la actual, además, pensaban que las gentes del Mediodía peninsular knon vos obedescerán, faciendo vos partición que queredes facer, ca tienen que son propios de la Corona de Castilla»; y en cuanto a Vizcaya "como quier que es tierra apartada, siempre es obediente al rey de Castilla, e se cuenta del su señotio e pendón» ${ }^{149}$. Por encima del «síndrome portugués», que acompañó a Juan I hasta el sepulcro, se acabó imponiendo un elemental sentido de estado.

El tercer ejemplo lo encontramos en esa delicada coyuntura abierta en la Navidad de 1406: una minoridad y una guerta con Granada se iniciaban al mismo tiempo. Una poco creible tradición presenta a un grupo de nobles ofreciendo la corona al infante don Fernando frente a los derechos de su sobrino Juan II. Una oferta que el futuro conquistador de Antequera se negaria a aceptar y que enaltecería su figura de hombre leal.

Pensamos que la cuestión es mucho más simple: el sentido de Estado expresado en 1390 se reiteró sin mayores traumas en $1406^{150}$. Las Cortes de To-

146 R. Fenou: Voz «Estado/Estados», en Léxico de la Edad Media. Madrid 1982. p. 70, para referirse a dos casos concretos: 1380 y 1413.

147 B. GUENÉE: Ob. cit. p. 253. Se tefiere, en concreto a los problemas militares como los más importantes negotia regni en los que tuvo que intervenir el Parlamento inglés bajo Eduardo III, $\mathrm{y}$ a la defensa del pais como razón fundamental para la reunión en Francia de los Estados provinciales en la segunda mitad del siglo XIV.

148 Peto López De Ayala: «Crónica de Juan I». pp. 126-127.

149 Ibid. p. 127.

150 Gutierre DiEZ DE GAMES dice que a la muerte de Enrique III debantaronse luego en el teino algunas discordias, segund que suele ser en otros tiempos cuando los reyes son peque- 
ledo fueron el medio para que las ciudades «reçibiesen por rey e señor al dicho señor Rey don Juan su sobrino» bajo la tutela del infante y la reina viuda Catalina de Lancaster ${ }^{151}$.

Las cortes, en tan excelente prueba de fuego, fueron el instrumento de una doble legitimación: la de una empresa bélica y la de la sucesión a la corona por las vías ya consagradas. La fidelidad que las cortes expresan a un estado se diluye, evidentemente, en la fidelidad a una dinastía. Pero no hay duda que se trata de una vía absolutamente operativa ${ }^{152}$.

\section{Conclusión:}

De lo expuesto con anterioridad se deduciría que las cortes castellanas -..-esa es la única función que le otorgan autores hipercríticos como Pérez Prendes- aconsejan al tey debatiendo aquellas cuestiones que deben ser (aprobadas por todos».

Junto a este deber de consejo estaria otro de auxilio militar/económico. Poco importa que esos deberes tengan o no una raíz feudal en el sentido más estrictamente institucional del término. Ningún foro mejor que las cortes para aconsejar y auxiliar.

El detecho de los príncipes a imponer tributos, sobre todo cuando estaba por medio la defensa del pais, eta comunmente reconocido; nadie negaba frontalmente que los reyes pudieran pedir dinero a sus súbditos. Pero pocas veces las asambleas otorgaban íntegramente las sumas que los gobiernos reclamaban para mantener la política exterior; los acuerdos no eran absolutos ${ }^{153}$ y los regateos podían prolongarse en el tiempo. El caso de las cortes de Toledo de 1406 es significativo... aunque el pulso entre ciudades y poder dure solamente unos días.

Nos preguntamos al principio de este trabajo si las cortes castellanas en la transición de los siglos XIV al XV decidían en cuestiones de política exterior o, por el contratio, eran mero escenario de un forcejeo económico para el sostenimiento de las campañas.

Resulta evidente que el monarca no necesita reunir cortes cada vez que tiene que tomar una importante decisión de política exterior. Pérez Prendes ha recordado que Juan I no las convoca para la campaña de Portugal tras la muerte del rey Fernando: se limita a consultar con sus inmediatos colaboradores.... algunos de los cuales, además "decían quel Rey non debía entrat en Portugal segun los tratados fechos entre él e el rey de Portogabs 154. Tras el descalabro de

\footnotetext{
ños» aunque, de inmediato añade que el infante y Catalina de Lancaster «mantubieron el reino en paz e en justiçia e en grand asosiego mientras ellos bibieron" E/Victorial. Ed. A. Miranda. Madrid 1993. pp. 504-505.

151 Alvar Garcia DE SANTA MARÍA: ob. cit. pp. 19-20, habla de esta situación con la mayor naturalidad.

152 Al margen del sentido de sacro o elegido que se quiera otorgar a linaje real. J.M. NiETO: Fundamentos ideologicos del poder real en Castilla (siglas XIII-XVI). Madrid 1988. p. 66.

153 J. STRAYER: Ob. iti. pp. 75-76 de forma especial.

154 J. PÉREZZ PRENDES: Ob at. P. 131.

Hiqpania, LlX/1, núm. 201 (1999) 115-148
} 
Aljubarrota, sin embargo, la situación cambia y las cortes se reunen con regularidad. En las de Valladolid de 1385, cuando se habla de reorganizar el Consejo, se esgrimen cuatro razones: la primera es uporque los fechos de la guerra, los quales son agora muy mas e mayores que fasta aquín, así lo exigian ${ }^{155}$.

Enrique III llamó a cortes con motivo de la guerra con Portugal (cortes de Segovia de 1396), o de la ruptura de hostilidades con Granada (Toledo 1406). Sin embargo, de la documentación disponible no se deduce que las cortes planeen las líneas maestras ni los detalles de la política exterior. Se limitan a discutir sobre las sumas reclamadas por el rey pata sostener el esfuerzo armado ${ }^{156}$. Un juego que se enmarcaría en esa "dialéctica de poder entre rey y reino" que algunos autores han considerado como una de las razones de ser del parlamentarismo medieval ${ }^{157}$.

Durante algún tiempo, y por las razones antes apuntadas, el tercer estado pudo llegar a creerse imprescindible en la toma de decisiones. Pudo pensar incluso que, cuando se le llamaba a la defensa del teipo o a la promoción de una guerra justa que era cuestión de todos, el gobierno estaba haciendo algo más que pedirle apoyo para salir de un aprieto o para emprender una política exterior de altos vuelos. Los tepresentantes de las ciudades pudieron imaginar en tales tesituras que el viejo y cerrado sistema trifuncional - los que combaten, los que rezan, los que trabajan - no estaba adaptado a las nuevas realidades del Bajo Medievo ${ }^{158}$ y había llegado la hora de plantar cara a las viejas categorias sociales dirigentes.

En Francia el desengaño se produciría con el fracaso de los Estados por tomar el poder, que culminatá en $1413^{15 \%}$.

Para el caso castellano creemos que es ilustrativo el irregular eco cronístico con que se acogen en el siglo XV las distintas reuniones de cortes: las del momento y las del pasado. Como ejemplo de estas últimas, las del reinado de Enque III aunque en sus sesiones se debatieran importantes problemas de política exteriot ${ }^{160}$.

155 Cortes... vol. II. p. 333.

156 A las tesis sostenidas por Colmeiro y Pérez Prendes, añádanse también las observaciones de M.A. LADERo sobre finanzas y relaciones exteriores con las cortes como telón de fondo en "Cortes de Castilla y León y fiscalidad regia (1369-1429)» en Las Cortes de Castillay Loón en la Edad Media, vol. I. pp. 365-370.

157 F.O. SAYLES: The King's Parliament of England Londres 1979. pp. 19-20.

158 R. FEDOU: L'etat au Moyen Age. p. 164.

159 Ibid. p. 166, refiriéndose a la ordenanza Cabochienne que llegó a ser papel mojado.

160 Cojamos tres ejemplos, referidos a las cortes de Toledo de 1406. Fernán PÉrEz Dr GuZMán dirá que el «Rey se movió a la guerra e vino a Toledo, e alli mandó ajuntar todas sus gentes, e hizo cortes para haber dineros y ordenar en los hechos de guerra». "Generaciones y semblanzas». p. 700. Gutierre Diez de GAMES dice «Partió el rey de Madrid e vinose a Toledo. Estando alli ordenando los fechos de lo guerra, diole alli al rey grand dolenzia...n. E/ Victorial. p. 504. Más tardiamente, Pedro de Escavias dice utan grande deseo avia de fazer guerra a los moros que, con toda su pasión viniendo para ge la facer e aviendo para ello mandado llamar a todas las gentes de sus rreynos, adoleçió e murió en la çibdad de Toledon. Repertorio de Principes de España. Ed. M. Garcia Jaén 1972. p. 324. 
La capacidad de maniobra de las cortes castellanas en torno a 1400 en lo que a relaciones internacionales se refiere, se desenvuelve en unos términos que poco tienen que ver con los actuales ${ }^{161}$.

Una situación que tiene su paralelalismo en otra: la de su supuesta capacidad para la elaboración de leyes. Legislar en el Medievo es algo muy distinto que legislar en un estado en el que se ha consagrado la división de poderes ${ }^{162}$.

Hablar de nacimiento del Estado Moderno para las entidades políticas del Renacimiento supone, igualmente, hablar de algo muy distinto de aquello que surgió como resultado de las revoluciones burguesas.

$Y$, puestos a hablar de anacronismos ¿por qué no recordar otro?: el de la identificación de las cortes castellanas del Medievo única y exclusivamente con el tercer estado. Bajo Enrique III, como bajo todos los monarcas de su dinastía, también los representantes de la nobleza y del clero eran cortes ${ }^{163}$.

\footnotetext{
161 Basta para ello remitirse a esas rutinarias confirmaciones de treguas con los vecinos a los que nos hemos referido a lo largo de este trabajo.

162 cf. E. Mitre: «A ochocientos años de las ¿primeras? cortes hispánicas (León 1188): Mitos políticos y memoria histórica en la formacón del parlamentarismo europeos. En Majurga 22 (Homenatge a Alvaro Santamaria. vol. 1). Palma de Mallorca 1989 p. 423.

163 A propósito del papel de la nobleza en las cortes, e incluso de lo imprescindible de su presencia durante prácticamente toda la Edad Media cf. mi «La Nobleza y las Cortes de Castilla y León", en Las Cortes de Castilla y León en la Edad Media, vol. II pp. 44-98.

Hìpania, LIX/1, núm. 201 (1999) 115-148
} 